\title{
Comprehensive identification of HSP70/HSC70 Chaperone Clients in Human Cells
}

Seung Woo Ryu ${ }^{1,2}$, Rose Stewart ${ }^{1,2}$, Chase Pectol ${ }^{3}$, Nicolette Ender ${ }^{1,2}$, Oshadi Wimalarathne $^{1,2}$, Ji-Hoon Lee ${ }^{1,2}$, Carlos P. Zanini ${ }^{4}$, Antony Harvey ${ }^{5}$, Jon Huibregtse ${ }^{2}$, Peter Mueller ${ }^{4}$, and Tanya T. Paull ${ }^{1,2 *}$

${ }^{1}$ The Howard Hughes Medical Institute and ${ }^{2}$ The Department of Molecular Biosciences, The University of Texas at Austin, Austin, TX 78712 USA, ${ }^{3}$ The Department of Chemistry, Texas A\&M University, College Station, Texas $77842,{ }^{4}$ Department of Statistics \& Data Sciences, University of Texas at Austin, Austin, TX 78712, ${ }^{5}$ Thermo Fisher Scientific, Austin, TX 78728. *corresponding author, tpaull@utexas.edu

keywords: chaperone, HSC70, HSP70, protein homeostasis 


\section{Abstract}

The HSP70 family of chaperones are the front-line of protection from stress-induced misfolding and aggregation of polypeptides in most organisms and are responsible for promoting the stability, folding, and degradation of clients to maintain cellular protein homeostasis. Here we demonstrate quantitative identification of HSP70 and HSC70 clients using an ubiquitin-mediated proximity tagging strategy and show that, despite their high degree of similarity, these enzymes have largely non-overlapping specificities. Both proteins show a preference for association with newly synthesized polypeptides but each responds differently to changes in the stoichiometry of proteins in obligate multi-subunit complexes. In addition, expression of an ALS-associated SOD1 mutant protein induces changes in HSP70 and HSC70 client association and aggregation toward polypeptides with predicted disorder, indicating that there are global effects from a single misfolded protein that extend to many clients within chaperone networks. Together these findings show that the ubiquitin-mediated UBAIT fusion system can efficiently isolate the complex interactome of HSP chaperone family proteins under normal and stress conditions. 


\section{Introduction}

Every cell has a finely tuned balance of protein expression, folding, complex formation, localization, and degradation that is specific to its growth state and environmental cues. Many pathological states involve changes in this balance, resulting in loss of regulatory control or loss of resilience during stress [1,2]. While gene expression is now quantitatively measured at the level of nucleic acids and polypeptides, determining the status of cells with respect to protein homeostasis is still a challenge, as we lack the tools to examine folding of individual proteins and the functionality of multi-component complexes quantitatively on a global scale.

The front line of defense against challenges to protein homeostasis are cellular chaperones - proteins which recognize unfolded, aggregated, or unstable polypeptides [3]. These ATP-dependent enzymes serve as a buffer to ensure that unfolded or aggregated polypeptides are either degraded or shielded within chaperone complexes or large protein-RNA assemblies [4]. The HSP70 family of chaperones is conserved in all organisms and, together with HSP90 chaperones and a host of co-chaperones including the HSP40 family, are thought to be responsible for recognition of nascent unfolded proteins and protein aggregates [5-7]. In addition, HSP70 enzymes respond to heat and other forms of stress that result in protein destabilization and also contribute to protein degradation [8]. Mammals have two primary classes of HSP70: HSC70, which is constitutively expressed, and HSP70, which is present in normally growing cells but is also dramatically induced during heat exposure, other forms of stress, or depletion of HSC70 [9]. In addition, organelle-specific forms of HSP70 also serve specialized functions such as the mitochondria-specific GRP75 (HSPA9) and ER-specific GRP78 (HSPA5) [10].

HSC70 and HSP70 are $85 \%$ identical to each other and are thought to have similar cellular roles [9]. One of the most important of these is to contribute to the folding of nascent polypeptides, and both $\mathrm{HSC70}$ and HSP70 have been reported to associate with translating 
ribosomes $[11,12]$. In yeast, the SSA family of HSP70 chaperones are grouped functionally with "chaperones linked to protein synthesis" (CLIPS) due to polysome association and similarities in transcriptional regulation in response to stress [13]. In addition, recent evidence suggests that HSP70 chaperones are essential for ongoing translation in mammalian cells, as the cessation of translation in response to heat is due to loss of the chaperones from actively translating ribosomes [14]. HSC70/HSP70 also safeguard proteins against aggregation, localize aggregated or misfolded proteins to stress granules or $\mathrm{P}$ bodies, promote correct trafficking of membrane-associated factors, and in some cases promote degradation via the proteasome or autophagy pathways [6-8].

While HSC70 (expressed from the HSPA8 gene) and HSP70 (expressed from the $H S P A 1 A / B$ genes) chaperones are generally considered to be redundant, there is substantial evidence supporting a division of functional roles. Deletion of HSPA1A and HSPA1B genes in mouse models generates sensitivity to stress and genomic instability but otherwise viable and fertile animals, whereas deletion of HSPA8 is lethal in vertebrates $[9,15]$. The HSPA8 gene from humans is able to complement yeast cells deficient in all cytoplasmic SSA1-4 HSP70 genes whereas HSPA1A cannot [16], suggesting that the properties of these two chaperones are not identical and that their client specificities may also be distinct.

Some of the clients (targets) of HSP70 chaperones have been determined empirically by investigation of specific proteins and their binding partners, but this has not been investigated on a global scale due to the transient nature of many chaperone-client interactions and the presumably large number of cellular clients [17]. Recent work identified the interactome of the ribosome-specific SSB1 and SSB2 chaperones in budding yeast using ribosome profiling, showing that these proteins associate with $\sim 80 \%$ of nascent polypeptides [18]; however, the clients of cytosolic HSP70 proteins have not been identified comprehensively in yeast or mammalian cells. There have been several studies examining the interactomes of chaperones using affinity purification coupled with mass spectrometry (AP-MS) and meta-analysis of 
physical and functional interactions in budding yeast which have illuminated the extensive associations between HSP90 complexes, HSP70 complexes, associated co-chaperones, proteasome components, and other cofactors in eukaryotes [19-24]. These have primarily been focused on HSP90 interactors, but some clients of HSP70 have been identified, particularly in budding yeast [19-21]. Although AP-MS is a powerful technique, it is limited by the fact that only interactions at the time of collection are able to be identified, biasing results towards the most abundant targets. In addition, large protein complexes may be isolated when only one or a few components of the complex actually interact with the chaperone.

Here we use a ubiquitylation-based strategy [25] to covalently link chaperones to their binding partners, and identify the clients and cofactors of constitutive HSC70 and heat inducible HSP70 in human cells. We find that HSP70 and HSC70 are largely non-overlapping for client association under normal growth conditions, although both chaperones show a bias toward binding to newly-synthesized polypeptides. Consistent with this role, HSC70 preferentially associates with proteins normally found in multi-component complexes but lack their partners proteins which are normally degraded. Lastly, expression of low levels of a misfolded protein drastically changes the client association landscape for HSC70 toward proteins with intrinsic disorder, suggesting that this chaperone is poised to alter its profile in response to subtle changes in the concentrations of misfolded proteins in cells.

\section{Results}

\section{Identification of UBAIT clients}

To identify chaperone binding partners, we employed a recently developed technique for the identification of protein-protein interactions that utilizes ubiquitin fusion proteins to covalently trap a protein of interest to its binding partners [25] ("UBAIT", Figure 1A). Fusion of ubiquitin to the C-terminus of a bait protein generates a UBAIT protein, which can be charged by the ubiquitin E1 enzyme and transferred to an E2 protein. The E2-charged UBAIT can react in 
trans with lysine residues on proteins that interact with the bait protein, resulting in a stable amide linkage between the bait and interactors. The ubiquitin moiety of the UBAIT carries a K48R mutation to block potential K48 chain formation that can lead to proteasome degradation of the UBAIT. One of the primary advantages of this system is that interacting proteins accumulate as covalent ubiquitination conjugates to the bait protein, so that even transient binding partners can be readily identified by mass spectrometry. We tagged human HSC70 and HSP70 chaperones with ubiquitin at the C-terminus and a biotinylation signal for BirA and a V5 epitope tag at the $\mathrm{N}$-terminus. The biotin tag allows us to carry out the isolation of UBAIT conjugates under denaturing conditions, eliminating the presence of proteins that are associated with the target protein in non-covalent complexes. An important control is to express the UBAIT with deletion of the C-terminal Gly-Gly residues of the ubiquitin moiety (" $\Delta G G$ "), which prevents conjugation of the UBAIT. Inducible expression of the wild-type HSP70 and HSC70 UBAITs in human cells generated a ladder of larger products, consistent with covalent trapping of the UBAIT with client proteins or co-chaperones (Figure 1B); the $\triangle$ GG UBAITs did not generate conjugates, as expected. We know that an HSP70 enzyme with a C-terminal ubiquitin fusion is functional, based on experiments in S. cerevisiae strain lacking all four HSP70 orthologs (SSA14). In these experiments, expression of a yeast SSA1 UBAIT $\triangle G G$ fusion fully complemented a $\Delta s s a 1-4$ deleted strain for viability (data not shown).

To identify high-confidence chaperone binding partners of human HSC70 and HSP70, we used human osteosarcoma (U2OS) cell lines containing stably-integrated, doxycyclineinducible HSC70-UBAIT (wild-type and $\Delta G G$ ) and HSP70-UBAIT (wild-type and $\Delta G G$ ) chaperones and grew these cells for 3 days after chaperone induction. We performed 12 wildtype UBAIT isolations and an equal number of control $\Delta \mathrm{GG}$ isolations, each starting with $3 \mathrm{mg}$ of total cellular protein, which were all performed under denaturing conditions followed by labelfree quantification of the isolated material as well as the total cell lysates by mass spectrometry (LC-MS/MS)(Figure 1C)[26]. We compared each of the identified proteins in wild-type and 
control $\triangle G G$ isolations to generate an enrichment ratio, and used a bootstrapping method to calculate p-values for likelihood of interaction (see Materials and Methods). Lastly, we identified the most significant interactions using Benjamini-Hochberg correction to control the false positive rate [27]. The 24 isolations were analyzed together in one group, and two additional biological repeats of this procedure were performed, each with 12 wild-type and $12 \Delta G G$ isolations. All of the samples were generated from a single U2OS cell line over the course of approximately two weeks and the samples for each group were collected and analyzed independently. Using this workflow we identified an average of 1409 interactors for the three HSC70 UBAIT experiments, with 763 proteins common to all three sets (Figure 1D, E, Table S1). The HSP70 UBAITs yielded fewer binding partners, with an average of 772 potential interactors, with 214 proteins shared among all three sets. Examples of HSC70 and HSP70 target enrichment data shown in Figure S1.

The UBAIT strategy relies upon cellular enzymes to conjugate the fused ubiquitin to targets [28]. To ensure that the binding partners we identified are actually specific to the chaperones and not nonspecifically associating with ubiquitin, we created biotin-V5-tagged ubiquitin-only constructs (wild type and $\Delta \mathrm{GG}$ ) to serve as an additional control for the experiments and performed one set (12 wild-type and $12 \Delta G G$ samples) of isolations, which identified 52 unique proteins. Comparison of this set with the chaperone UBAIT data showed a relatively small number of the binding partners of HSC70 and HSP70 were shared with biotinV5-ubiquitin only (Figure 1E, Table S1), 16 from the HSC70 list and 11 from HSP70, with 5 shared between them. Although many proteins can be ubiquitinated in cells [29], it is clear from this analysis that the vast majority of the interacting proteins identified with HSC70 and HSP70 are actually chaperone-binding factors.

Analysis of the proteins identified as interactors of HSC70 and HSP70 shows many known co-chaperones and binding partners of these chaperones (Figure 1F). Those that are common to both enzymes include the HSP90AA1/AB1 chaperones that fold substrates 
cooperatively with HSP70 family enzymes [30] as well as the "bridging" cofactor STIP1 (HOP) that binds to HSP70 and HSP90 [31]. We also recovered HIP (ST13) that regulates chaperone activity [32] and several nucleotide exchange factors for the HSP70 family including BAG2, and BAG3 as well as several members of the J-domain-containing HSP40 family that regulate the catalytic cycle of HSP70 enzymes: DNAJA1, DNAJC7, DNAJC10, DNAJC13, DNAJB2, and DNAJB4. We also identified interacting HSP70 family members which regulate substrate binding and release: HSPH1, HSPA4, and GRP170 (HYOU1) [33], and other compartmentspecific members of the HSP70 family (HSPA2, HSPA9B, and HSPE1) and several members of the chaperonin family (CCT proteins) [34,35].

Although several cofactors were observed to bind to both HSC70 and HSP70, some of the interacting cofactors were specific for HSC70. For instance, the DNAJC10 and DNAJC13 HSP40 proteins, which promote ATP hydrolysis by HSP70 chaperones, were only identified with statistically significant binding for HSC70, suggesting that the occupancy of these cofactors with the constitutive chaperone is much greater than with the heat-inducible form. In contrast, the nucleotide exchange factor HSPBP1 is only found with HSP70, not with HSC70, suggesting that this regulatory protein binds stably to the heat-inducible form.

Besides known co-chaperones and adaptors for HSP70 enzymes, we observed a large number of cellular proteins that do not have known association with HSC70 or HSP70 and are likely to be client proteins (Table S1). The interactors are predicted to be localized in many cellular compartments, consistent with the role of HSC70 and HSP70 in promoting the folding and localization of cytosolic, nuclear, and membrane proteins with diverse functions [6].

The high degree of overlap between the 3 UBAIT experiments performed, particularly for HSC70, indicates that the UBAIT strategy combined with the sample isolation, mass spectrometry, and statistical analysis, yields reproducible and statistically significant chaperonebinding targets. These results can be considered as an HSC70/HSP70 chaperone-binding snapshot of this cell line at a specific point in time; however, we do not suggest that these define 
an immutable client repertoire. We have observed client-binding patterns change over time within the same cell line, suggesting that chaperone clients are sensitive to environmental as well as intracellular stress conditions, as discussed in more detail below.

The HSP70 family of proteins are part of a larger system of protein quality control and have been shown to regulate both proteasome-mediated degradation of proteins as well as chaperone-mediated autophagy [8]. The experiments in Figure 1 were performed with a K48R version of ubiquitin in the UBAIT experiments to block degradation of the fusion protein [36], but we were also interested in how this mutation affects the recovery of HSC70 and HSP70 clients. We performed the UBAIT experiment with K48 wild-type versions of ubiquitin and found that the number of binding partners identified in the HSP70 UBAIT did not change significantly from the three independent experiments that were performed with K48R ubiquitin (Figure S2). However, with $\mathrm{HSC} 70$, we were unable to identify targets with statistically significant binding (only 1 protein identified after filtering for non-specific interactions and controlling the false discovery rate). These results may suggest that client proteins associated with $\mathrm{HSC70}$ and ubiquitin constitute a potent degradation signal, while the equivalent complex with HSP70 does not. These results are consistent with reports showing that $\mathrm{HSC70}$ is required for efficient proteasome-mediated degradation of some clients [37,38], and evidence for HSC70/HSP70 proteins in chaperone-assisted ubiquitin-proteasome degradation [39].

\section{Comparison with BiolD}

To validate the results from the UBAIT-based interaction screen, we also analyzed HSP70 clients using an orthogonal method - BiolD [40,41]. This strategy involves fusion of a bait protein to the biotin ligase BirA, which results in biotinylation of proteins bound to the bait. Transient interactions are captured with this method, similar to the UBAIT fusions, and targets are also recovered with high stringency biotin-streptavidin interactions. Here we inducibly expressed an HSP70 fusion with $A$. aeolicus biotin ligase (BiolD2)[41] as well as biotin ligase alone, and 
performed 12 isolations for each with streptavidin beads using the same isolation procedures as were used in the UBAIT experiments. After controlling the false discovery rate with BenjaminiHochberg and excluding the targets isolated with biotin ligase alone, we identified 438 polypeptides as binding partners of HSP70 (Table S2). Examples of targets recovered with the BiolD2-HSP70 fusion are also shown in Figure S3. Of these 438 targets, 252 (58\%) were also found with the HSP70 UBAIT fusion in at least one of the 3 sets of UBAIT experiments performed, indicating that there is reasonable overlap between the clients identified by these methods. Co-chaperones and chaperone-associated factors were also well-represented in this group, including HSPH1, HSPA2, HSPA4, HSPA5/BIP, HSPA9, HSPE1, STIP1/Hop, ST13, Chaperonins, DNAJ proteins, BAG2, and BAG3 (Figure S3).

\section{HSP70 and HSC70 preferentially bind to newly synthesized proteins}

HSC70 and HSP70 orthologs are known to be associated with translating ribosomes $[11,19,42]$. To determine if the clients of HSP70 and HSC70 are biased toward newly-translated proteins, we used a Stable Isotope Labeling with Amino acids in Cell culture (SILAC)-based approach to distinguish between newly-made proteins and older proteins in the cells. To test this strategy, U2OS cells were grown for at least five doublings in media containing standard L-lysine and Larginine, and then switched into heavy $\left({ }^{13} \mathrm{C},{ }^{15} \mathrm{~N}\right) \mathrm{L}$-lysine and L-arginine media for one, two, or three days before harvesting (Figure 2A, top). Doxycycline induction of chaperones was started at time "0" to ensure that all chaperone UBAIT protein was expressed in heavy isotope. Total proteins in the lysates were analyzed for light/heavy ratios in tryptic peptides, which showed that the overall light/heavy ratios decreased with the length of heavy media pulse, as expected, with some proteins showing less change in the ratio over time (long-lived) whereas other proteins changed at a higher than average rate (short-lived) (Figure 2A).

To use this system in the context of our UBAIT chaperone isolations, U2OS cells expressing tagged HSC70 or HSP70 UBAITs were incubated with light media for at least five 
doublings before induction of UBAIT expression with doxycycline (Figure 2B, top panel). The cells were changed to heavy media at the time of induction and grown for either 1 or 2 days before harvesting. Chaperone UBAIT isolation was then performed as in Figure 1, with 12 wildtype UBAIT isolations performed for each chaperone. Binding partners were analyzed for light/heavy ratios by mass spectrometry, and the total patterns of these ratios for HSC70 and HSP70 validated partners show an average of 0.95 and 0.63 light/heavy log ratios for a 1 day pulse, and -0.31 and -1.22 for a 2-day pulse, respectively ("actual" distributions in Figure 2B). Since every protein has a unique turnover rate, we also calculated the expected light/heavy ratio for each protein for the duration of the pulse, based on the results from the total lysates in our 1 and 2-day SILAC experimental dataset, with an assumption that the heavy isotope incorporation rate is linear over 2 days (Figure 2B, C). This "expected" ratio for each protein comes from the total lysate data and therefore represents the overall turnover rate for that protein in the cell, whereas the UBAIT target data shows the ratio specifically for the polypeptides captured by the UBAIT tagged chaperone.

Comparison of the UBAIT actual light/heavy ratios versus the expected light/heavy ratios for HSC70 and HSP70 UBAIT binding partners shows that there are more UBAIT partners that are significantly younger (heavy) relative to total protein present in the lysate (Figure 2D, E, F, Table S3). Shaded areas in Figure 2D and 2E show proteins with significantly different ratios in the actual versus expected values, the majority of which are younger than expected. This preference is observed for both HSC70 and HSP70 and is consistent with the idea that a majority of unfolded or misfolded targets are bound by these chaperones either at the ribosome or shortly after translation. Both short-lived and long-lived proteins were observed in the UBAIT datasets, thus there was no obvious preference for polypeptides showing rapid turnover. 
One important biological scenario that requires HSC70/HSP70 chaperone function is the maintenance of proper stoichiometry within multi-component complexes. "Orphan" proteins that lack essential binding partners are rapidly degraded in eukaryotes in a manner that requires HSP70 family enzymes [43-46], and the maintenance of stoichiometry within multi-component complexes in eukaryotes was recently suggested to occur through a co-translational process $[43,47]$. To test whether HSC70 or HSP70 specifically interact with proteins in multi-subunit complexes that are destined to be degraded in the absence of their obligate binding partners, we chose a multi-subunit complex in which one member of the complex is dependent on at least one other member for its stability. Mre11, a DNA repair factor, is absolutely essential for the stability of its binding partner, Rad50 [48]. Rad50 is not observed consistently as an HSC70 or HSP70 UBAIT binding partner under normal growth conditions (Table S1). We reduced levels of Mre11 by shRNA depletion in U2OS cells and found that this reduced not only Mre11 but also the total amount of Rad50 protein, as expected (Figure 3A). We performed 6 UBAIT isolations of tagged HSC70 and HSP70 from cells with the Mre11 shRNA expressed, and found that levels of Rad50 bound to HSC70 increased 3.2-fold compared to samples without Mre11 depletion. This was not the case for HSP70, which showed no increase in Rad50 association. These results collectively suggest that, in this case, HSC70 specifically binds to an orphan protein that is missing its obligate binding partners, while the heat-inducible HSP70 does not play this role.

We also were interested in testing whether expression of known obligate partners could reduce levels of $\mathrm{HSP} 70 / \mathrm{HSC} 70$ client binding. For this we chose a protein that was consistently identified as one of the highest-ranked binding partners of HSP70 and HSC70, the ATP1A1 component of the sodium/potassium pump. It has been demonstrated that the stability of ATP1A1 is dependent on its heterodimer binding partner ATP1B1 [49]. ATP1B1, in contrast to ATP1A1, is not enriched for either HSC70 or HSP70 in our UBAIT experiments (Table S1). We hypothesized that the level of ATP1A1 expressed in this cancer cell line exceeds that of its 
obligate partner ATP1B1 and thus ATP1A1 is recognized by HSP70/HSC70 constitutively in these cells. In this case, we should be able to reduce the level of ATP1A1 binding to the chaperones by overexpression of ATP1B1. To test this, we overexpressed ATP1B1 by transient expression in the HSC70 and HSP70 UBAIT cells, and monitored the levels of both proteins. As expected, overexpression of ATP1B1 increased the stability of ATP1A1 (Figure 3B). In addition, the levels of ATP1A1 observed in the 6-sample UBAIT isolation of HSP70 decreased 3.6-fold with ATP1B1 expression compared to the untreated group of samples. Unlike the example with Mre11 and Rad50, in this case the levels of ATP1A1 bound to HSC70 did not change.

To further characterize the relationship of "orphan" proteins and chaperone binding, we chose the MSH2-MSH6 heterodimeric complex, a mismatch repair recognition enzyme in which MSH6 is strongly dependent on MSH2 for stability [50]. Like ATP1A1, MSH6 is recovered as an interactor with UBAIT-tagged chaperones, but MSH2 is not (Table S1). We overexpressed MSH2 in HSC70 and HSP70 UBAIT cells, performed a 6-replicate experiment for each tagged chaperone, and observed a 1.9-fold reduction in MSH6 levels associated with the HSP70 UBAIT specifically, but not with HSC70 (Figure 3C), similar to the result with ATP1A1 and ATP1B1. Taken together, these depletion and overexpression experiments suggest that HSC70 and HSP70 are monitoring levels of orphan proteins and that in some cases there seem to be specific interactions with one but not both of the chaperones. The experiments in which we have partially restored missing binding partners show that these interactions can be modulated in predictable ways by changing the expression of their obligate partners.

\section{Expression of a misfolded protein changes the landscape of HSC7O binding partners}

Efficient control of protein homeostasis is critical for all cells but particularly for some tissues, for instance neurons and other non-dividing cells in the mammalian brain [51]. The consequences of protein misfolding in neuronal cells can include neurodegeneration, in which case misfolded proteins are implicated in each disorder that have pathological effects in specific neuronal 
populations [52]. We tested the binding of HSC70 and HSP70 to one of these factors, the superoxide dismutase mutant $\mathrm{A} 4 \mathrm{~V}(\mathrm{SOD} 1 \mathrm{~A} 4 \mathrm{~V})$ associated with a subset of familial ALS and the cause of highly penetrant and rapid motor neuron loss [53]. The A4V mutation in SOD1 promotes the formation of misfolded but soluble oligomers that are thought to be associated with neurotoxicity [54]. Here we expressed SOD1(A4V) co-translationally with GFP (GFP-P2ASOD1) using a BacMam virus in our HSC70 and HSP70 UBAIT cells at levels approximately 10fold higher than endogenous SOD1, and isolated targets from 12 samples for each chaperone (with $12 \Delta G G$ controls). We compared these results to an equal number of samples in which GFP expression alone was induced. We observed significantly increased binding of SOD1 to both chaperones with SOD1(A4V) overexpression under these conditions (Figure 4A).

We expected that the expression of a misfolded protein might cause one or both chaperones to exhibit lower levels of binding to endogenous clients because of the acquired association with SOD1(A4V). We did see this, with both HSC70 and HSP70 showing a loss of $44 \%$ of the bound partners observed in the absence of SOD1(A4V) expression. Unexpectedly, we also observed new partners upon SOD1(A4V) overexpression, approximately half as many as were lost (Figure 4B, Table S4). We examined this new set of acquired binding partners (206 for HSP70 and 227 for HSC70) and found that the newly bound partners of HSC70 were significantly increased for both polypeptide length and for predicted disorder based on the TANGO algorithm that estimates intermolecular beta-sheet protein aggregation [55](Figure 4C). The binding partners of HSC70 and HSP70 in the absence of misfolded protein expression do not exhibit any significant differences in these parameters in any of the other trials compared to the total lysate (data not shown).

We also utilized a method to isolate detergent-resistant protein aggregates [56] from the cells expressing GFP only or GFP plus SOD1(A4V) to determine if there are any changes in protein aggregation. We performed isolations and mass spectrometry-based quantitation from 3 biological replicates with cells expressing GFP only or GFP plus SOD1(A4V) and identified a 
total of 2433 proteins in the aggregate fractions (Figure 4D). The majority of these (1520) did not change significantly with SOD1(A4V) expression, but we found that 620 proteins were recovered at reduced levels while 293 were more enriched with expression of the misfolded SOD1. These 293 proteins were not related to the proteins identified in our UBAIT isolations but, similar to the HSPA8 UBAIT targets, they did show a bias toward proteins with higher predicted disorder (TANGO score)[55].

To determine if the apparent change in binding partners observed in the UBAIT experiment was due to the high level of SOD1(A4V) expression, we also repeated this experiment with lower levels of SOD1(A4V) expression by reducing the amount of BacMam virus, again analyzing 12 wild-type and $12 \Delta \mathrm{GG}$ controls (Figure 4E). Here, SOD1(A4V) expression levels were only 1.6-fold over the endogenous protein level. SOD1 was still observed binding to both HSC70 and HSP70, albeit with lower overall efficiency compared to the experiment with higher SOD1(AV4) expression. Nevertheless, we still observed $36 \%$ loss of clients with HSC70, and 4\% loss with HSP70 under these conditions (Figure 4F). In addition, we still observed a gain in novel HSP70 and HSC70 clients, and the HSC70 clients again specifically exhibited a higher predicted level of intrinsic disorder (Figure 4G). Here the proteins bound by HSC70 in response to SOD1(A4V) expression exhibited not only higher TANGO scores for beta-sheet aggregation propensity but also higher WALTZ scores, which estimates amyloid-forming potential in proteins based on experimentally-determined physical properties [57].

Collectively, the results with SOD1(A4V) expression show that expression of a misfolded protein, even at low levels, can cause dramatic shifts in chaperone binding patterns for both HSC70 as well as HSP70. These include not only association with the misfolded species, but also a reorganization of client binding. For HSC70 specifically, there appears to be a shift to proteins with different physical features that include factors with intrinsically disordered regions and longer polypeptides. 


\section{Discussion}

\section{Employing UBAIT to identify a complex set of interactors}

We have established in this work that the UBAIT fusion system can be used to profile complex interactomes. This method has previously been used to identify partners of bait proteins that have relatively few targets $[28,58]$, but here we show that this strategy can be used on a large scale to identify hundreds of interacting partners. UBAITs have the advantage that even transient interactions can be captured in covalent association between the bait and the binding protein. This is useful in normalization between samples, as the wild-type and $\Delta \mathrm{GG}$ forms of the fusion protein are both isolated and quantitated. In contrast, it is more difficult to normalize samples with BiolD fusions, as the BiolD fusion protein is not reliably isolated during the procedure. The UBAIT $\triangle G G$ isolations also provide an excellent negative control in these experiments since they express the identical bait protein, only lacking the last two glycine residues of ubiquitin. This provides a stringent comparison for nonspecific interactions, and allows for confident identification of even low-level interactors.

Mass spectrometry reliably identifies the most abundant polypeptides in a biological sample but low-level targets may be missed, depending on the mass/charge ratio of individual peptides and the mixture of other proteins present during the analysis [59]. For these reasons, failure to identify a given peptide or protein in a complex mixture is not necessarily a confident indicator of its absence. In this work we used a large number of replicate isolations (12 per set), with an equal number for the $\Delta G G$ controls, and also performed 3 sets per chaperone in order to acquire sufficient data for low level target identification. We used a bootstrapping method to determine the statistical probability for likelihood of each outcome, only taking those exceeding the $95 \%$ confidence interval. This strategy, combined with Benjamini-Hochberg methods to control the False Discovery Rate, allow us to identify low-level interactors (see Materials and Methods for details). 
HSP70 and HSC70 Chaperones as non-redundant monitors of stress states

HSP70 and HSC70 targets have historically been very challenging to identify and quantify because of the large number of potential client interactions as well as the transient nature of these interactions. We have demonstrated in this study that it is possible to globally interrogate HSP70/HSC70 chaperone binding partners in human cells and that these interactions change in response to physiologically relevant sources of stress. We find that both HSP70 and HSC70 clients are biased toward newly synthesized proteins but they are largely non-overlapping in their binding preferences, thus these enzymes should not be considered identical in function or associations. The changes in both HSC70 binding partners as well as the aggregation propensity of proteins prone to misfolding with SOD1(A4V) expression strongly suggest that the protein homeostasis system as a whole is dramatically altered by the introduction of a single disordered protein, conditions which are likely relevant to early stages of human pathology involving disordered protein expression.

\section{Materials and Methods}

Plasmid Construction

Constructs based on the pcDNA5 vector (Thermo Fisher Scientific) were used to express fulllength HSPA1A and HSPA8 with N-terminal V5 and BirA epitope tags and a C-terminal in-frame K48R ubiquitin (pTP3923 and pTP3921, respectively) under the control of a doxycyclineinducible CMV promoter. pcDNA5/FRT/TO V5 HSPA8 was a gift from Harm Kampinga (Addgene plasmid \# 19514; http://n2t.net/addgene:19514; RRID:Addgene_19514) and pcDNA5/FRT/TO V5 HSPA1A was a gift from Harm Kampinga (Addgene plasmid \# 19510; http://n2t.net/addgene:19510; RRID:Addgene_19510)[60]. Versions containing deletions of the gly-gly amino acids at the end of ubiquitin were generated (pTP3924 and pTP3922, respectively) as well as versions containing ubiquitin only (pTP3939 and pTP3940). A lentivirus construct 
containing the biotin ligase BirA was generated from the lentiCRISPR v2 backbone (Addgene 52961)[61] and a construct containing BirA (a gift from Mauro Modesti) to make pTP3530 and used to make lentivirus with the helper plasmids pCMV-dR8.91 (Delta 8.9), and VSV-G. pLentiCRISPR v2 was a gift from Feng Zhang (Addgene plasmid \# 52961;

http://n2t.net/addgene:52961; RRID:Addgene_52961). BioID2 contructs were made by inserting BiolD2 (Addgene 92308) as an N-terminal fusion into HSPA8 and HSPA1A pcDNA5 constructs (Addgene 19514 and 19510) to make pTP4458 and pTP4459, respectively, retaining a V5 epitope tag in the linker. mycBiolD2-13X Linker-MCS was a gift from Kyle Roux (Addgene plasmid \# 92308 ; http://n2t.net/addgene:92308 ; RRID:Addgene_92308). Cloning details available upon request. An MRE11-specific shRNA (5' ACAGGAGAAGAGAUCAACUUUGuuaauauucauagCAAAGUUGAUCUCUUCUCCUGU $\left.-3^{\prime}\right)$ was expressed under doxycyclin control from pRSITEP-U6Tet-(sh)-EF1-TetRep-2A-Puro (Cellecta, Inc.). BacMam constructs were generated from pAceBac1 (Geneva Biotech) with the Tet-On CMV promoter from pcDNA5 replacing the polyhedrin promoter. This construct was used to make bacmams expressing full-length MSH2 (pTP4651) and V5-tagged SOD1(A4V)P2A-GFP (pTP4497) with MSH2 from MSH2/pBluescript [62](Addgene \#16453), and SOD1 from SOD1/pLX304 (DNASU \# HsCD00440778), respectively. The A4V mutation in SOD1 was made using QuikChange mutagenesis (Agilent). A version of the SOD1 construct with SOD1 removed (containing V5-tagged GFP only, pTP4552) was generated from pTP4497. These were used to generate bacmids and baculovirus according to manufacturer instructions for the bac-to-bac system (Thermo Fisher Scientific). ATP1B1 was overexpressed by transient transfection using a pcDNA3-based construct from GenScript (\#OHu18298D). Plasmid sequences and cloning details available upon request.

\section{Mammalian Cell Culture}


We used a human osteosarcoma cell line (U2OS) containing an FRT recombination site integrated into the genome adjacent to a CMV promoter blocked by two copies of the Tet operator (Invitrogen FIp-In ${ }^{T M}$ T-Rex ${ }^{T M}$ system). HSPA1A, HSPA8, and Ubiquitin UBAIT constructs were transfected into these cells and selected with hygromycin according to manufacturer's instructions. BirA-expressing lentivirus was then added and cells were selected with $1 \mu \mathrm{g} / \mathrm{ml}$ puromycin. Cells were then grown in Dulbecco's Modified Eagle Medium (DMEM) with $7.5 \%$ FBS (Tet-minus, Invitrogen) with 100 units $/ \mathrm{ml}$ penicillin-streptomycin, $15 \mu \mathrm{g} / \mathrm{ml}$ Blasticidin, $200 \mu \mathrm{g} / \mathrm{ml}$ Hygromycin, and $1 \mu \mathrm{g} / \mathrm{ml}$ puromycin. Expression of UBAIT constructs were induced by addition of $1 \mu \mathrm{g} / \mathrm{ml}$ doxycycline the day after seeding in $15 \mathrm{~cm}$ dishes and harvested after 3 days. Expression of BiolD2 constructs were induced by addition of $1 \mathrm{ug} / \mathrm{ml}$ doxycycline with $50 \mathrm{uM}$ of biotin supplement the day after seeding in $15 \mathrm{~cm}$ dishes and harvested after 3 days. Trypsinized cells were washed in PBS and flash frozen using liquid nitrogen and kept at $-80^{\circ} \mathrm{C}$ until use.

\section{Lentivirus production and transduction}

HEK-293T cells (ATCC) were grown in Dulbecco's Modified Eagle Medium (DMEM) with 7.5\% FBS. 293T cells were plated in 6 well dishes and allowed to grow to near confluence. A solution with optiMEM and plasmids was made using $1.2 \mu \mathrm{g}$ pLX304 vector containing shRNA for gene of interest, 100ng of VSV-G, 500ng of pCMV-dR8.91 ( $\Delta$ 8.9) and brought to $100 \mu \mathrm{L}$ with OptiMEM. $7 \mu \mathrm{L}$ of FuGENE was combined with the Opti-MEM solution, incubated for 25 minutes at room temperature and then added to the 293 T cells in 6 wells. The media was changed a day later and left for 24 hours. The media was harvested, then replaced and again harvested 24 hours later. The collected media was combined and filter sterilized using $0.45 \mu \mathrm{m}$ filters and then stored at $-80^{\circ} \mathrm{C}$ until needed. U2OS cells were plated in 6-well plates and allowed to reach near confluency. The media was removed and $1 \mathrm{ml}$ of the viral aliquots. The cells were grown overnight and then media was replaced with 24 hours later. The following day, cells were 
transferred to a T-75 flask with selection agent added. Cells were incubated for approximately 1 week until control cells without virus died. For transient transfection of the ATP1B1 expression plasmid, U2OS cells were plated in $15 \mathrm{~cm}$ dish for prior to additional of doxycycline for expression of UBAIT constructs. $12 \mu \mathrm{g}$ of plasmid was added with Calcium phosphate per $15 \mathrm{~cm}$ dish as previously described [63].

\section{Streptavidin Isolation of biotin-tagged UBAIT targets}

Each U2OS cell pellet (from four $15 \mathrm{~cm}$ dishes) were lysed in $1 \mathrm{ml}$ of lysis buffer (8M Urea, 50mM Tris pH8, $5 \mathrm{mM} \mathrm{CaCl}_{2}, 500 \mathrm{mM} \mathrm{NaCl}, 0.1 \%$ SDS, 2.5mM PMSF (Calbiochem), and EDTAfree Protease Inhibitor (Pierce)). Lysates were sonicated twice for 30 sec separated by 30 sec rest. A volume of lysate containing $3 \mathrm{mg}$ protein was brought to a final volume of $1 \mathrm{~mL}$ in lysis buffer; urea concentration was then reduced to $1 \mathrm{M}$ with dilution buffer $(50 \mathrm{mM}$ Tris $\mathrm{pH} 8,500 \mathrm{mM}$ $\mathrm{NaCl}, 0.1 \% \mathrm{SDS}$ ) by gradual addition while vortexing. At least two samples of $3 \mathrm{mg}$ each were typically obtained from each pellet. M-280 Streptavidin Dynabeads (Invitrogen, 11206D) were washed twice in dilution buffer, resuspended in the same volume, and $120 \mu$ l bead resuspension was added to each sample and samples were rotated overnight at room temperature. Beads were then resuspended in $1.5 \mathrm{ml}$ wash buffer (1M Urea, $50 \mathrm{mM}$ Tris $\mathrm{pH} 8,500 \mathrm{mM} \mathrm{NaCl}, 0.1 \%$ SDS). Buffer was removed and beads were then washed twice for $>30 \mathrm{~min}$ in wash buffer, followed by $500 \mathrm{mM} \mathrm{LiCl}$ for $15 \mathrm{~min}$, then $0.1 \%$ SDS, $0.2 \%$ SDS, and $0.5 \%$ SDS for 30 min each. All wash steps were performed in $1.5 \mathrm{ml}$ solution while rotating at room temperature. Bound protein was eluted by boiling beads at $100^{\circ} \mathrm{C}$ for $5 \mathrm{~min}$ in $50 \mu \mathrm{L} 1 \%$ SDS solution containing 50 mM 2-mercaptoethanol. The elution step was repeated and eluates were combined and stored at $-20^{\circ} \mathrm{C}$.

Filter aided sample preparation, mass spectrometry and Quantification 
Frozen eluates were boiled for $2 \mathrm{~min}$ at $100^{\circ} \mathrm{C}$ then any residual beads were removed with a magnet. Samples were diluted with 600 ul of UA buffer (8M Urea, 0.1M Tris pH 8.8). MicroCon ${ }^{\circledR}$ 30 centrifugal filter units (Millipore, MRCF0R030) were equilibrated with $20 \%$ ACN, $2 \%$ formic acid solution and centrifuged at 14,000xg for 10 min prior to use. Samples were loaded onto the filters then washed 3 times with $400 \mu \mathrm{L}$ UA buffer. After washing, samples were incubated for 5 min at room temperature with $400 \mu \mathrm{L} 50 \mathrm{mM}$ DTT in UA buffer to reduce disulfide bonds. Samples were centrifuged and then alkylated with $400 \mu \mathrm{L} 50 \mathrm{mM}$ iodoacetamide by incubation for $5 \mathrm{~min}$ at room temperature followed by centrifugation. Samples were de-salted with $400 \mu \mathrm{L}$ $40 \mathrm{mM}$ ammonium bicarbonate (ABC) 3 times. $100 \mu \mathrm{L} 40 \mathrm{mM}$ ABC containing $0.5 \mu \mathrm{L}$ of trypsin gold (Promega, V528A) in PBS was added to each sample and samples were incubated overnight at $37^{\circ} \mathrm{C}$ in a closed, humidified chamber. Peptides were eluted by centrifugation and filtrate was reserved in tube; filters were then washed with $100 \mathrm{ul} 20 \% \mathrm{ACN}, 2 \%$ formic acid solution and filtrate was combined with eluted peptides in $A B C$ buffer. Collected samples were lyophilized at room temperature. Dried samples were resuspended in $10 \mu \mathrm{L} 0.1 \%$ formic acid with $0.1 \%$ trifluoroacetic acid then de-salted with C18 tips (Pierce, QK224796) according to manufacturer's protocol. The final samples were resuspended in $80 \%$ ACN $2 \%$ formic acid for LC-MS analysis. All centrifugations were done at 14,000xg for $10 \mathrm{~min}$ at room temperature unless otherwise noted. Protein identification by LC-MS/MS was provided by the University of Texas at Austin Proteomics Facility on an Orbitrap Fusion following previously published procedures [56]. Raw files were analyzed using label-free quantification with Proteome Discoverer 2.2. The details of workflow for PD 2.2 are available upon request.

\section{Statistics Testing and analysis}

Proteome Discover 2.2 results were further refined by two additional methods in order to control the false discovery rate. First, all proteins were cross-referenced for common contaminants, in 
which case they were removed from final analysis. Any polypeptides with less than two unique peptides identified were removed from final analysis. Refined data was then normalized by levels of total HSP70 or HSC70 in order to correct for variation of recovery between samples. Missing data was imputed using weighted low abundance resampling, which replaces missing values with random values sampled from the lower $5 \%$ of the detected values, with heavier weighting toward higher values.

To compare negative control $\triangle$ GG UBAIT with experimental wild-type UBAIT samples, we took the ratio of average intensity measurements from wild-type UBAITS divided by $\Delta G G$ UBAITS for each protein identified to create an enrichment ratio. A bootstrapping method was then used to create a distribution of possible ratios (1000) for each protein by randomly assigning wild type or $\Delta G G$ values from each protein. Finally, we compared the actual ratio to the hypothetical distribution of randomized ratios and computed the $p$-value of the actual ratio from the quantile. Proteins with ratios less than top 5\% percentiles were considered to be significant. In order to control the false discovery rate (FDR) from multiple hypothesis testing, we used the Benjamini-Hochberg procedure [64] for each of the experiments using an FDR of 0.05 (see Table S1).

\section{Stable isotope labeling using amino acids in cell culture (SILAC)}

U2OS cells containing HSPA1A and HSPA8 UBAITs were grown in Light Lysine/Arginine Dulbecco's Modified Eagle Medium (DMEM) with 10\% dialyzed FBS for at least 2 weeks (at least 5 cell doublings). U2OS cells were plated in $15 \mathrm{~cm}$ dishs with $20 \mathrm{ml}$ of Light DMEM. The next day, media was replaced by Heavy Lysine $\left({ }^{13} \mathrm{C}_{6},{ }^{15} \mathrm{~N}_{2} \mathrm{~L}\right.$-Lysine-2HCl$)$, Arginine $\left({ }^{13} \mathrm{C}_{6},{ }^{15} \mathrm{~N}_{4}\right.$ L-Arginine-HCl) DMEM (Thermo Fisher Scientific) with 10\% dialyzed FBS containing $1 \mathrm{ug} / \mathrm{ml}$ doxycycline and grown for either 1 day or 2 days. Cells were harvested and frozen as described above. Cell pellets were lysed and UBAIT targets were isolated as described above. 12 samples were used for each chaperone (wild-type UBAIT only). These samples, as well as 3 total lysates, 
were analyzed by mass spectrometry for protein identification as well as light/heavy ratios for each peptide. Total cell lysate light/heavy ratio data was used to experimentally derive two data points for each enriched protein identified (day 1 and day 2). Using day 0 as $100 \%$ light, three points were used to calculate a linear slope explaining change of light/heavy ratio for each individual protein. The averaged slope from the three points was used to calculate expected light/heavy ratios for UBAIT targets (the "expected" values, see Table S3). Light/heavy ratios were also measured from 12 wild-type UBAIT isolations from day 1 and day 2 SILAC experiments (the "actual" values, Table S3). No $\Delta G G$ isolations were performed in this case, but proteins positively identified as HSC70 and HSP70 binding partners in experiments described in Figure 1 were compared with the expected value using a one-sample t-test.

Isolation of detergent-resistant aggregates

This procedure was performed as previously described [56].

\section{References}

1. Sweeney P, Park H, Baumann M, Dunlop J, Frydman J, Kopito R, et al. Protein misfolding in neurodegenerative diseases: implications and strategies. Transl Neurodegener. 2017;6. doi:10.1186/s40035-017-0077-5

2. Hipp MS, Park S-H, Hartl FU. Proteostasis impairment in protein-misfolding and aggregation diseases. Trends Cell Biol. 2014;24: 506-514. doi:10.1016/j.tcb.2014.05.003

3. Hartl FU, Hayer-Hartl M. Converging concepts of protein folding in vitro and in vivo. Nat Struct Mol Biol. 2009;16: 574-581. doi:10.1038/nsmb.1591

4. Nillegoda NB, Wentink AS, Bukau B. Protein Disaggregation in Multicellular Organisms. Trends Biochem Sci. 2018;43: 285-300. doi:10.1016/j.tibs.2018.02.003

5. Mayer MP. Hsp70 chaperone dynamics and molecular mechanism. Trends Biochem Sci. 2013;38: 507-514. doi:10.1016/j.tibs.2013.08.001

6. Finka A, Sharma SK, Goloubinoff P. Multi-layered molecular mechanisms of polypeptide holding, unfolding and disaggregation by HSP70/HSP110 chaperones. Front Mol Biosci. 2015;2. doi:10.3389/fmolb.2015.00029 
7. Meimaridou E, Gooljar SB, Chapple JP. From hatching to dispatching: the multiple cellular roles of the Hsp70 molecular chaperone machinery. J Mol Endocrinol. 2008;42: 1-9. doi:10.1677/JME-08-0116

8. Fernández-Fernández MR, Gragera M, Ochoa-Ibarrola L, Quintana-Gallardo L, Valpuesta JM. Hsp70 - a master regulator in protein degradation. FEBS Lett. 2017;591: 2648-2660. doi:10.1002/1873-3468.12751

9. Kabani M, Martineau C. Multiple Hsp70 Isoforms in the Eukaryotic Cytosol: Mere Redundancy or Functional Specificity? Curr Genomics. 2008;9: 338-348. doi:10.2174/138920208785133280

10. Daugaard $M$, Rohde $M$, Jäättelä $M$. The heat shock protein 70 family: Highly homologous proteins with overlapping and distinct functions. FEBS Lett. 2007;581: 3702-3710. doi:10.1016/j.febslet.2007.05.039

11. Beckmann RP, Mizzen LE, Welch WJ. Interaction of Hsp 70 with newly synthesized proteins: implications for protein folding and assembly. Science. 1990;248: 850-854.

12. Frydman J, Hartl FU. Principles of chaperone-assisted protein folding: differences between in vitro and in vivo mechanisms. Science. 1996;272: 1497-1502.

13. Albanèse V, Yam AY-W, Baughman J, Parnot C, Frydman J. Systems Analyses Reveal Two Chaperone Networks with Distinct Functions in Eukaryotic Cells. Cell. 2006;124: 7588. doi:10.1016/j.cell.2005.11.039

14. Shalgi R, Hurt JA, Krykbaeva I, Taipale M, Lindquist S, Burge CB. Widespread Regulation of Translation by Elongation Pausing in Heat Shock. Mol Cell. 2013;49: 439-452. doi:10.1016/j.molcel.2012.11.028

15. Hunt CR, Dix DJ, Sharma GG, Pandita RK, Gupta A, Funk M, et al. Genomic instability and enhanced radiosensitivity in Hsp70.1- and Hsp70.3-deficient mice. Mol Cell Biol. 2004;24: 899-911.

16. Tutar $Y$, Song $Y$, Masison DC. Primate chaperones Hsc70 (constitutive) and Hsp70 (induced) differ functionally in supporting growth and prion propagation in Saccharomyces cerevisiae. Genetics. 2006;172: 851-861. doi:10.1534/genetics.105.048926

17. Clerico EM, Tilitsky JM, Meng W, Gierasch LM. How Hsp70 Molecular Machines Interact with Their Substrates to Mediate Diverse Physiological Functions. J Mol Biol. 2015;427: 1575-1588. doi:10.1016/j.jmb.2015.02.004

18. Döring K, Ahmed N, Riemer T, Suresh HG, Vainshtein Y, Habich M, et al. Profiling SsbNascent Chain Interactions Reveals Principles of Hsp70-Assisted Folding. Cell. 2017;170: 298-311.e20. doi:10.1016/j.cell.2017.06.038

19. Taipale M, Tucker G, Peng J, Krykbaeva I, Lin Z-Y, Larsen B, et al. A quantitative chaperone interaction network reveals the architecture of cellular protein homeostasis pathways. Cell. 2014;158: 434-448. doi:10.1016/j.cell.2014.05.039 
20. Truman AW, Kristjansdottir K, Wolfgeher D, Ricco N, Mayampurath A, Volchenboum SL, et al. Quantitative proteomics of the yeast Hsp70/Hsp90 interactomes during DNA damage reveal chaperone-dependent regulation of ribonucleotide reductase. J Proteomics. 2015;112: 285-300. doi:10.1016/j.jprot.2014.09.028

21. Gong Y, Kakihara Y, Krogan N, Greenblatt J, Emili A, Zhang Z, et al. An atlas of chaperone-protein interactions in Saccharomyces cerevisiae: implications to protein folding pathways in the cell. Mol Syst Biol. 2009;5. doi:10.1038/msb.2009.26

22. Zhao R, Davey M, Hsu Y-C, Kaplanek P, Tong A, Parsons AB, et al. Navigating the Chaperone Network: An Integrative Map of Physical and Genetic Interactions Mediated by the Hsp90 Chaperone. Cell. 2005;120: 715-727. doi:10.1016/j.cell.2004.12.024

23. Taipale M, Krykbaeva I, Koeva M, Kayatekin C, Westover KD, Karras GI, et al. Quantitative Analysis of Hsp90-Client Interactions Reveals Principles of Substrate Recognition. Cell. 2012;150: 987-1001. doi:10.1016/j.cell.2012.06.047

24. Rizzolo K, Huen J, Kumar A, Phanse S, Vlasblom J, Kakihara Y, et al. Features of the Chaperone Cellular Network Revealed through Systematic Interaction Mapping. Cell Rep. 2017;20: 2735-2748. doi:10.1016/j.celrep.2017.08.074

25. O'Connor HF, Lyon N, Leung JW, Agarwal P, Swaim CD, Miller KM, et al. UbiquitinActivated Interaction Traps (UBAITs) identify E3 ligase binding partners. EMBO Rep. 2015;16: 1699-1712. doi:10.15252/embr.201540620

26. Ankney JA, Muneer A, Chen X. Relative and Absolute Quantitation in Mass SpectrometryBased Proteomics. Annu Rev Anal Chem. 2018;11: 49-77. doi:10.1146/annurev-anchem061516-045357

27. Benjamini, Yoav, Hochberg, Yosef. Controlling the false discovery rate: a practical and powerful approach to multiple testing. J R Stat Soc Ser B. 1995;57: 289-300.

28. O'Connor HF, Lyon N, Leung JW, Agarwal P, Swaim CD, Miller KM, et al. UbiquitinActivated Interaction Traps (UBAITs) identify E3 ligase binding partners. EMBO Rep. 2015;16: 1699-1712. doi:10.15252/embr.201540620

29. Kim W, Bennett EJ, Huttlin EL, Guo A, Li J, Possemato A, et al. Systematic and Quantitative Assessment of the Ubiquitin-Modified Proteome. Mol Cell. 2011;44: 325-340. doi:10.1016/j.molcel.2011.08.025

30. Morán Luengo T, Kityk R, Mayer MP, Rüdiger SGD. Hsp90 Breaks the Deadlock of the Hsp70 Chaperone System. Mol Cell. 2018;70: 545-552.e9.

doi:10.1016/j.molcel.2018.03.028

31. Baindur-Hudson S, Edkins AL, Blatch GL. Hsp70/Hsp90 Organising Protein (Hop): Beyond Interactions with Chaperones and Prion Proteins. In: Blatch GL, Edkins AL, editors. The Networking of Chaperones by Co-chaperones. Cham: Springer International Publishing; 2015. pp. 69-90. doi:10.1007/978-3-319-11731-7_3 
32. Gebauer M, Zeiner M, Gehring U. Proteins interacting with the molecular chaperone hsp70/hsc70: physical associations and effects on refolding activity. FEBS Lett. 1997;417: $109-113$.

33. Bracher A, Verghese J. GrpE, Hsp110/Grp170, HspBP1/Sil1 and BAG domain proteins: nucleotide exchange factors for Hsp70 molecular chaperones. Subcell Biochem. 2015;78: 1-33. doi:10.1007/978-3-319-11731-7_1

34. Radons J. The human HSP70 family of chaperones: where do we stand? Cell Stress Chaperones. 2016;21: 379-404. doi:10.1007/s12192-016-0676-6

35. Daugaard $M$, Rohde $M$, Jäättelä $M$. The heat shock protein 70 family: Highly homologous proteins with overlapping and distinct functions. FEBS Lett. 2007;581: 3702-3710. doi:10.1016/j.febslet.2007.05.039

36. Chau V, Tobias J, Bachmair A, Marriott D, Ecker D, Gonda D, et al. A multiubiquitin chain is confined to specific lysine in a targeted short-lived protein. Science. 1989;243: 15761583. doi: $10.1126 /$ science. 2538923

37. Glazier AA, Hafeez N, Mellacheruvu D, Basrur V, Nesvizhskii Al, Lee LM, et al. HSC70 is a chaperone for wild-type and mutant cardiac myosin binding protein C. JCI Insight. 2018;3. doi:10.1172/jci.insight.99319

38. Bercovich B, Stancovski I, Mayer A, Blumenfeld N, Laszlo A, Schwartz AL, et al. Ubiquitindependent Degradation of Certain Protein Substrates in Vitro Requires the Molecular Chaperone Hsc70. J Biol Chem. 1997;272: 9002-9010. doi:10.1074/jbc.272.14.9002

39. Fernández-Fernández MR, Gragera M, Ochoa-Ibarrola L, Quintana-Gallardo L, Valpuesta JM. Hsp70 - a master regulator in protein degradation. FEBS Lett. 2017;591: 2648-2660. doi:10.1002/1873-3468.12751

40. Roux KJ, Kim DI, Burke B, May DG. BiolD: A Screen for Protein-Protein Interactions. Curr Protoc Protein Sci. 2018;91. doi:10.1002/cpps.51

41. Kim DI, Jensen SC, Noble KA, Kc B, Roux KH, Motamedchaboki K, et al. An improved smaller biotin ligase for BiolD proximity labeling. Zheng Y, editor. Mol Biol Cell. 2016;27: 1188-1196. doi:10.1091/mbc.E15-12-0844

42. Willmund $F$, del Alamo M, Pechmann S, Chen T, Albanèse V, Dammer EB, et al. The Cotranslational Function of Ribosome-Associated Hsp70 in Eukaryotic Protein Homeostasis. Cell. 2013;152: 196-209. doi:10.1016/j.cell.2012.12.001

43. Shiber A, Döring K, Friedrich U, Klann K, Merker D, Zedan M, et al. Cotranslational assembly of protein complexes in eukaryotes revealed by ribosome profiling. Nature. 2018;561: 268-272. doi:10.1038/s41586-018-0462-y

44. McClellan AJ, Scott MD, Frydman J. Folding and quality control of the VHL tumor suppressor proceed through distinct chaperone pathways. Cell. 2005;121: 739-748. doi:10.1016/j.cell.2005.03.024 
45. Park S-H, Bolender N, Eisele F, Kostova Z, Takeuchi J, Coffino P, et al. The cytoplasmic Hsp70 chaperone machinery subjects misfolded and endoplasmic reticulum importincompetent proteins to degradation via the ubiquitin-proteasome system. Mol Biol Cell. 2007;18: 153-165. doi:10.1091/mbc.e06-04-0338

46. Arndt V, Rogon C, Höhfeld J. To be, or not to be--molecular chaperones in protein degradation. Cell Mol Life Sci CMLS. 2007;64: 2525-2541. doi:10.1007/s00018-007-71886

47. Kamenova I, Mukherjee P, Conic S, Mueller F, El-Saafin F, Bardot P, et al. Co-translational assembly of mammalian nuclear multisubunit complexes. Nat Commun. 2019;10: 1740. doi:10.1038/s41467-019-09749-y

48. Stewart GS, Maser RS, Stankovic T, Bressan DA, Kaplan MI, Jaspers NG, et al. The DNA double-strand break repair gene hMre11 is mutated in individuals with an AtaxiaTelangiectasia-like disorder. Cell. 1999;99: 577-87.

49. Chow DC, Forte JG. Functional significance of the beta-subunit for heterodimeric P-type ATPases. J Exp Biol. 1995;198: 1-17.

50. Edelbrock MA, Kaliyaperumal S, Williams KJ. Structural, molecular and cellular functions of MSH2 and MSH6 during DNA mismatch repair, damage signaling and other noncanonical activities. Mutat Res. 2013;743-744: 53-66. doi:10.1016/j.mrfmmm.2012.12.008

51. Bourdenx M, Koulakiotis NS, Sanoudou D, Bezard E, Dehay B, Tsarbopoulos A. Protein aggregation and neurodegeneration in prototypical neurodegenerative diseases: Examples of amyloidopathies, tauopathies and synucleinopathies. Prog Neurobiol. 2017;155: 171193. doi:10.1016/j.pneurobio.2015.07.003

52. Sweeney P, Park H, Baumann M, Dunlop J, Frydman J, Kopito R, et al. Protein misfolding in neurodegenerative diseases: implications and strategies. Transl Neurodegener. 2017;6. doi:10.1186/s40035-017-0077-5

53. Corcia P, Couratier P, Blasco H, Andres CR, Beltran S, Meininger V, et al. Genetics of amyotrophic lateral sclerosis. Rev Neurol (Paris). 2017;173: 254-262. doi:10.1016/j.neurol.2017.03.030

54. Redler RL, Fee L, Fay JM, Caplow M, Dokholyan NV. Non-native Soluble Oligomers of $\mathrm{Cu} / \mathrm{Zn}$ Superoxide Dismutase (SOD1) Contain a Conformational Epitope Linked to Cytotoxicity in Amyotrophic Lateral Sclerosis (ALS). Biochemistry. 2014;53: 2423-2432. doi:10.1021/bi500158w

55. Fernandez-Escamilla A-M, Rousseau F, Schymkowitz J, Serrano L. Prediction of sequence-dependent and mutational effects on the aggregation of peptides and proteins. Nat Biotechnol. 2004;22: 1302-1306. doi:10.1038/nbt1012

56. Lee J-H, Mand MR, Kao C-H, Zhou Y, Ryu SW, Richards AL, et al. ATM directs DNA damage responses and proteostasis via genetically separable pathways. Sci Signal. 2018;11. doi:10.1126/scisignal.aan5598 
57. Maurer-Stroh S, Debulpaep M, Kuemmerer N, de la Paz ML, Martins IC, Reumers J, et al. Exploring the sequence determinants of amyloid structure using position-specific scoring matrices. Nat Methods. 2010;7: 237-242. doi:10.1038/nmeth.1432

58. O'Connor HF, Swaim CD, Canadeo LA, Huibregtse JM. Ubiquitin-Activated Interaction Traps (UBAITs): Tools for Capturing Protein-Protein Interactions. In: Mayor T, Kleiger G, editors. The Ubiquitin Proteasome System. New York, NY: Springer New York; 2018. pp. 85-100. doi:10.1007/978-1-4939-8706-1_7

59. Meyer B, Papasotiriou DG, Karas M. $100 \%$ protein sequence coverage: a modern form of surrealism in proteomics. Amino Acids. 2011;41: 291-310. doi:10.1007/s00726-010-06806

60. Hageman J, Kampinga HH. Computational analysis of the human HSPH/HSPA/DNAJ family and cloning of a human HSPH/HSPA/DNAJ expression library. Cell Stress Chaperones. 2009;14: 1-21. doi:10.1007/s12192-008-0060-2

61. Sanjana NE, Shalem O, Zhang F. Improved vectors and genome-wide libraries for CRISPR screening. Nat Methods. 2014;11: 783-784. doi:10.1038/nmeth.3047

62. Leach FS, Nicolaides NC, Papadopoulos N, Liu B, Jen J, Parsons R, et al. Mutations of a mutS homolog in hereditary nonpolyposis colorectal cancer. Cell. 1993;75: 1215-1225. doi:10.1016/0092-8674(93)90330-S

63. Lee JH, Paull TT. Purification and biochemical characterization of ataxia-telangiectasia mutated and Mre11/Rad50/Nbs1. Methods Enzym. 2006;408: 529-39.

64. Benjamini Y, Hochberg Y. Controlling the False Discovery Rate: A Practical and Powerful Approach to Multiple Testing. J R Stat Soc Ser B Methodol. 1995;57: 289-300. doi:10.1111/j.2517-6161.1995.tb02031.x

\section{Acknowledgements}

We thank the CBRS Proteomics Core Facility and Dr. Maria Person for assistance with mass spectrometry, Xuemei Wen for molecular biology assistance, and members of the Paull lab for helpful comments on the manuscript. We also thank Harm Kampinga for the HSPA8 and HSPA1A clones (Addgene plasmids \# 19514 and 19510)[60], Bert Vogelstein for the hMSH2 Clone E3 (Addgene plasmid \# 16453) [62], Feng Zhang for the lentiCRISPR construct (Addgene plasmid \# 52961)[61], Kyle Roux for the BiolD2 construct (Addgene plasmid \# 92308)[41], and Mauro Modesti for the BirA plasmid. 


\section{Figure Legends}

Figure 1. Global identification of HSPA1A and HSPA8 clients using UBAIT in human cells. (A) Schematic diagram of biotin/V5-HSP70/HSC70 UBAIT conjugation to bound targets. (B) Western blot of HSP70 and HSC70 UBAITs after streptavidin isolation from human U2OS cells treated with doxycycline ("Dox")(1ug/ml) for 3 days or untreated. (C) Schematic of experimental and statistical workflow used for the analysis of UBAIT-conjugated targets. 12 wild-type or $\Delta G G$ samples are first analyzed by LC-MS-MS using label free quantification then missing values are imputed by low abundance resampling (5\%). Wild-type and $\Delta G G$ values are used to calculate an enrichment ratio and also are bootstrapped to generate random enrichment ratio distribution (1000X). The actual enrichment ratio is compared with the bootstrapped distribution to obtain $\mathrm{p}$ values which are corrected for multiple testing hypotheses using Bonferroni correction. (D) Venn diagrams of HSC70 and HSP70 targets identified from 3 independent experiments, each with $\mathrm{N}=12$, all with $\mathrm{K} 48 \mathrm{R}$ ubiquitin fusions. (E) Venn diagram of proteins identified as significantly enriched from all three experiments compared to ubiquitin-only control. $(F)$ Co-chaperones and known chaperone interactors identified from D. All factors shown were identified at FDR 0.05. Black outline: enriched for HSC70 and HSP70 binding in all 3 sets for both chaperones; red outline: enriched for HSC70 in all 3 sets, no enrichment for HSP70; blue outline: enriched for HSC70 in all 3 sets, enriched for HSP70 in at least one set; green outline: enriched for HSP70 in all 3 sets, no enrichment for HSC70; purple outline: enriched for HSP70 in all 3 sets, enriched for HSC70 in at least one set. Fill colors show chaperones (grey), DNAJ proteins (green), nucleotide exchange factors (blue), other co-chaperones (orange or pink), chaperonins (purple).

Figure 2. HSC70 and HSP70 binding partners are enriched for newly synthesized proteins.

(A) top: schematic diagram of SILAC pilot experiment performed with U2OS cells; cells were grown in light arginine and lysine media prior to experiment for least 14 days. Media was changed to heavy arginine and lysine for 1, 2 or 3 days before harvesting. Protein in total 
lysates was analyzed for light/heavy ratios by label-free mass spectrometry and polypeptides identified from all three samples are shown. (B) top: Schematic view of SILAC UBAIT experiment used for 12 wild-type UBAIT samples from HSC70 and HSP70 at each time point. bottom: comparison of light/heavy ratios of HSP70 and HSC70 targets from the SILAC UBAIT isolations, only showing targets verified from UBAIT experiments performed in Figure 1. (C) Schematic showing method for calculation of expected light/heavy ratios. Total cell lysate light/heavy ratio data was used to experimentally derive two data points for each enriched protein identified. These two points were used to calculate a slope to obtain a theoretical expected light/heavy ratios for each UBAIT target. (D,E) Volcano plot of proteins enriched for HSP70/HSC70 association by comparing the actual ratio to the expected ratio for each protein, with significance $(Q$ value $=-\log 10$ of $p$ value $)$ on the $Y$ axis. $P$ values were calculated using a one-sample t-test, comparing the 12 "actual" ratios to the "expected" ratio. Proteins to the left of the $\mathrm{Y}$ axis are proteins that have lower light/heavy ratio than expected, while proteins to the right are proteins that have higher light/heavy ratio than expected. (F) Summary of results from (D) and $(E)$. Protein counts from the lower-than-expected category or the higher-than-expected category are summarized.

Figure 3. HSC70 and HSP70 association with proteins lacking binding partners. (A) top: schematic diagram of the Mre11/Rad50/Nbs1 complex showing that loss of Mre11 induces loss of Rad50. HSP70 and HSC70 UBAIT isolations were performed with or without depletion of endogenous Mre11 by shRNA ( $N=6)$. Levels of Rad50 associated with HSP70 or HSC70 UBAITs was measured using label free quantification. Western blot showing levels of Mre11, Rad50 and control proteins GAPDH and beta-actin in UBAIT cells with Mre11 shRNA as indicated. (B) top: schematic diagram of the ATP1A1/ATP1B1 complex showing that insufficient levels of ATP1B1 lead to loss of ATP1A1 while overexpression of ATP1B1 restores the complex and ATP1A1 stability. HSP70 and HSC70 UBAIT isolations were performed with or without 
overexpression of ATP1B1 $(\mathrm{N}=6)$. Levels of ATP1A1 associated with HSP70 or HSC70 UBAITs was measured using label free quantification. Western blot showing levels of ATP1A1, ATP1B1, and beta-actin in UBAIT cells with ATP1B1 expression as indicated. (C) top: schematic diagram of the MSH2/MSH6 complex showing that insufficient levels of MSH2 lead to loss of MSH2 while overexpression of MSH2 restores the complex and MSH6 stability. HSP70 and HSC70 UBAIT isolations were performed with or without overexpression of MSH2 $(\mathrm{N}=6)$. Levels of MSH6 associated with HSP70 or HSC70 UBAITs was measured using label free quantification. Western blot showing levels of MSH2, MSH6, and beta-actin in UBAIT cells with MSH2 expression as indicated.

\section{Figure 4. Expression of a misfolded protein changes the landscape of HSC70 binding}

partners. (A) HSP70 and HSC70 UBAIT isolations were performed in U2OS cells with either GFP or SOD1(A4V)-P2A-GFP high level overexpression $(\mathrm{N}=6)$; levels of SOD1 associated with HSP70 or HSC70 UBAITs was measured using label free quantification. (B) Venn diagrams showing proteins identified as enriched with either HSP70 or HSC70 UBAITs; red circle indicates targets gained with SOD1(A4V) expression in HSC70 UBAIT cells. (C) Summary of average WALTZ [57] and TANGO [55] scores as well as polypeptide length of proteins enriched with UBAITs in cells expressing GFP or SOD1(A4V)-P2A-GFP. Welch's T test was used to compute $p$-values and red box indicates significant $p$ values corresponding to targets gained with SOD1(A4V) expression in HSC70 UBAIT cells. (D) Detergent-resistant protein aggregates were isolated and analyzed by mass spectrometry from UBAIT-expressing cells with either GFP or SOD1(A4V) expression ( $\mathrm{N}=3$ ). Summary of proteins identified that increased, decreased, or were statistically indistinguishable in aggregate fraction with SOD1(A4V) expression. Welch's T test was used to compute p-values (E) HSP70 and HSC70 UBAIT isolations were performed with lower level overexpression (approximately 2-fold compared to endogenous) protein SOD1(A4V)-P2A-GFP is overexpressed in low amount compared to figure $A(N=6)$; levels of 
SOD1 associated with HSP70 or HSC70 UBAITs was measured using label free quantification.

(F) Venn diagrams showing proteins identified as enriched with either HSP70 or HSC70 UBAITs.

(F) Summary of average WALTZ [57] and TANGO [55] scores as well as polypeptide length of proteins enriched with UBAITs in cells expressing GFP or SOD1(A4V)-P2A-GFP. Welch's T test was used to compute $p$-values and red box indicates significant $p$ values corresponding to targets gained with SOD1(A4V) expression in HSC70 UBAIT cells. 
PioRxiv preprint doi: https://doi.org/10.1101/865030; this version posted December 4, 2019. The copyright holder for this preprint (which was hot certified by peer review) is the author/funder, who has granted bioRxiv a license to display the preprint in perpetuity. It is made available under aCC-BY 4.0 International license.

A

\begin{tabular}{|c|c|}
\hline Bio-V5: & HSC70/HSP70 \\
\hline
\end{tabular}

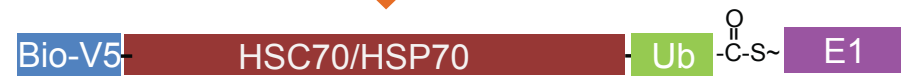

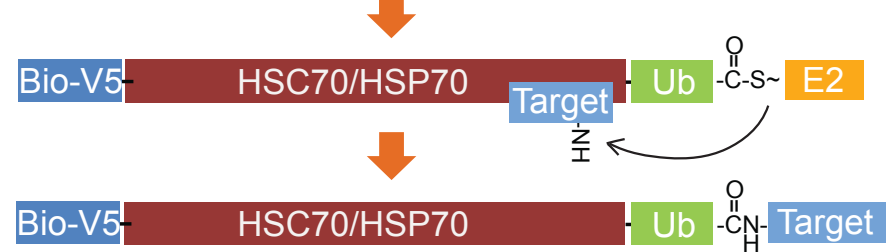

B

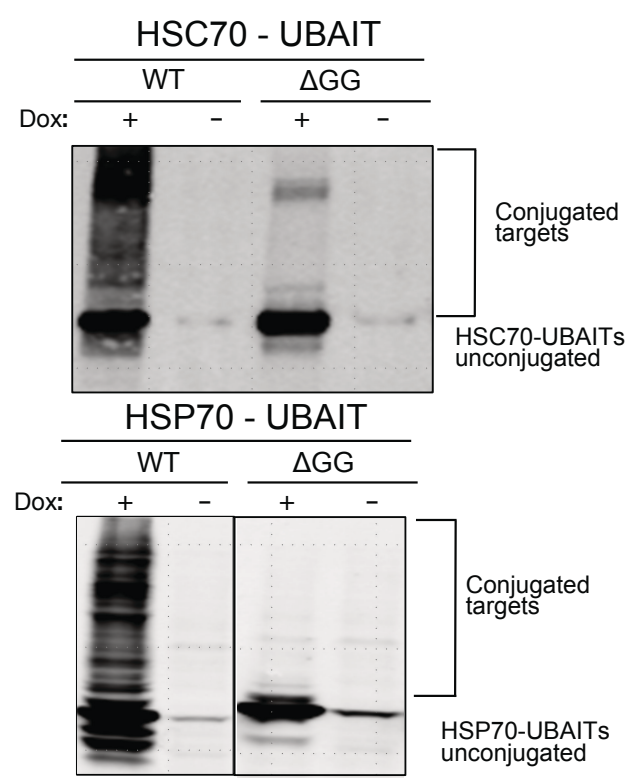

D $\mathrm{HSC70}$

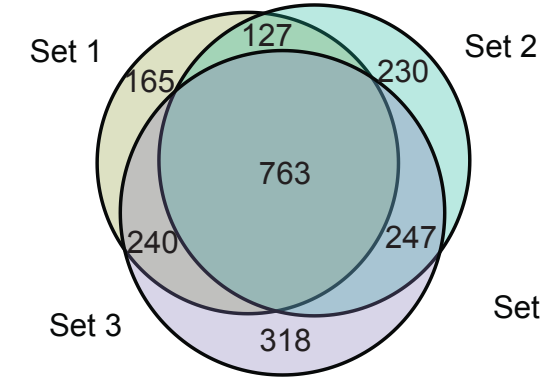

$E$

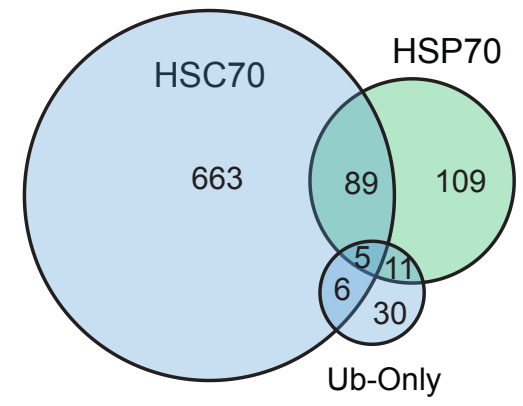

HSC70 or HSP70

12 WT UBAIT

a

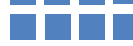
口ם

Streptavidin IP
Harvest and Lysis

HSC70 or HSP70

12 dGG UBAIT

Filter-aided sample preparation, Zip-tip

Orbitrap LC-MS/MS

Proteome Discoverer

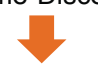

Total data distribution from file (normalized by IP-bait)

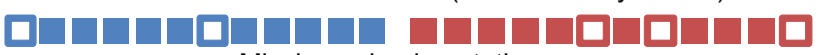
Missing value imputation: Low abundance resampling (5\%)

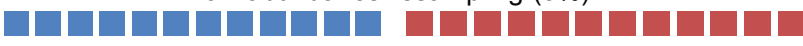

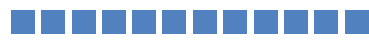

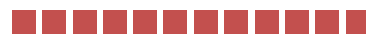
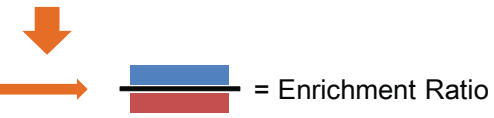

Bootstrapping for enrichment ratio distribution

$=\square=\begin{gathered}\text { Enrichment ratio of randomly } \\ \text { distributed values (1000x) }\end{gathered}$

95\% percentile calculation: actual vs random distribution

Percentile $=p$ value

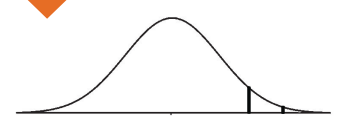

HSC70 and HSP70 chaperone and co-chaperone interactions:

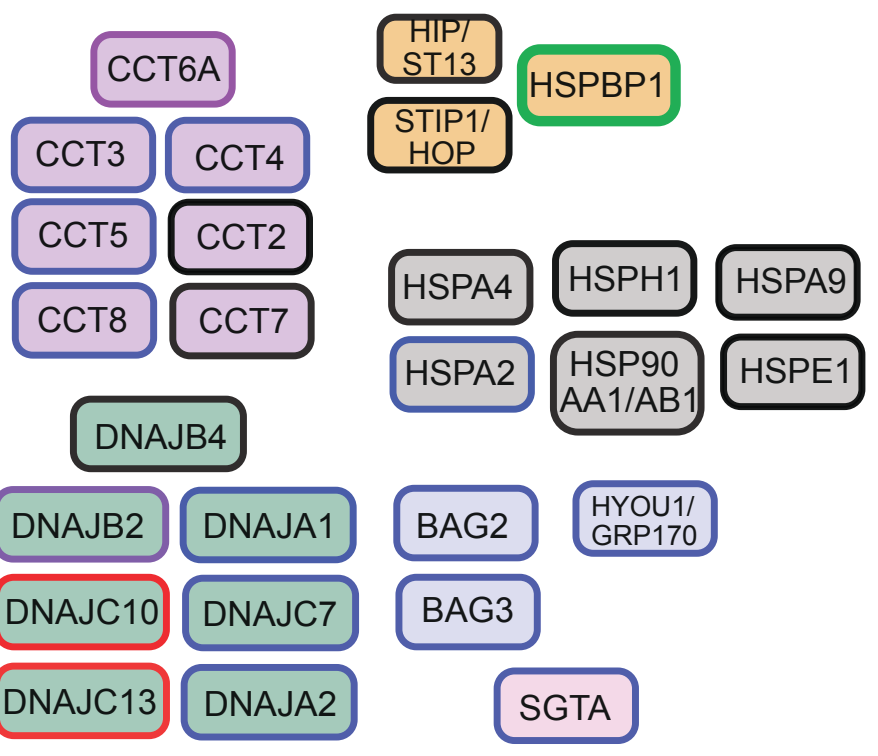


bioRxiv preprint doi: https://doi.org/10.1101/865030; this version posted December 4, 2019. The copyright holder for this preprint (which was not certified by peer review) is the author/funder, who has granted bioRxiv a license to display the preprint in perpetuity. It is made available under aCC-BY 4.0 International license.

A
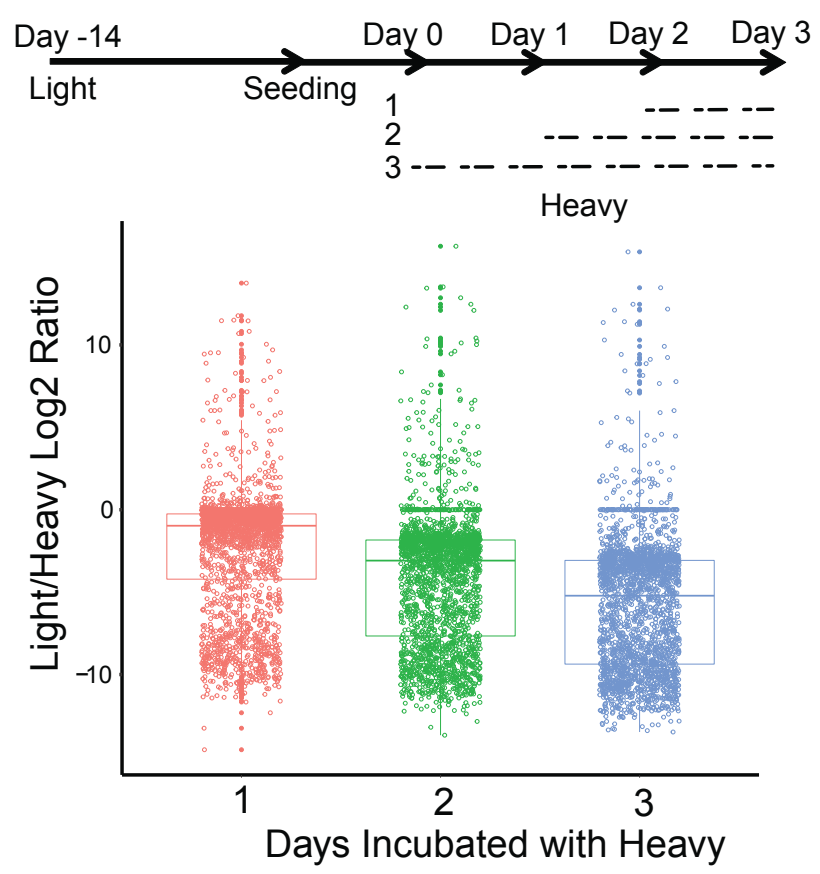

C

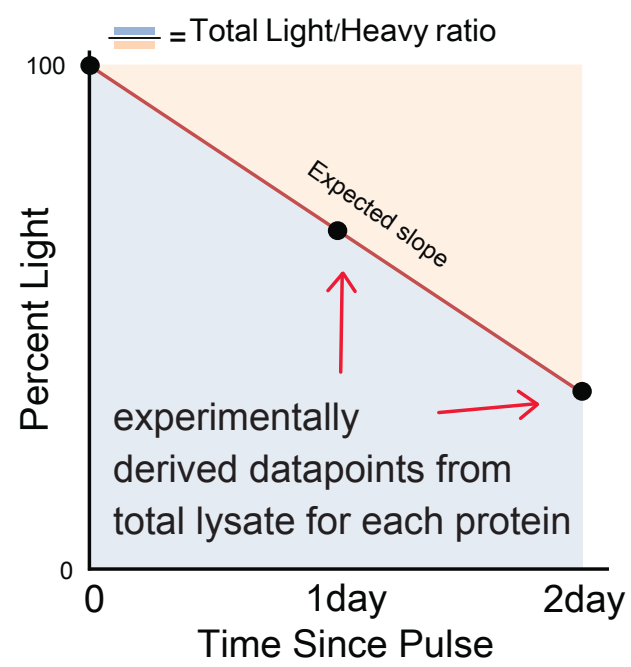

E

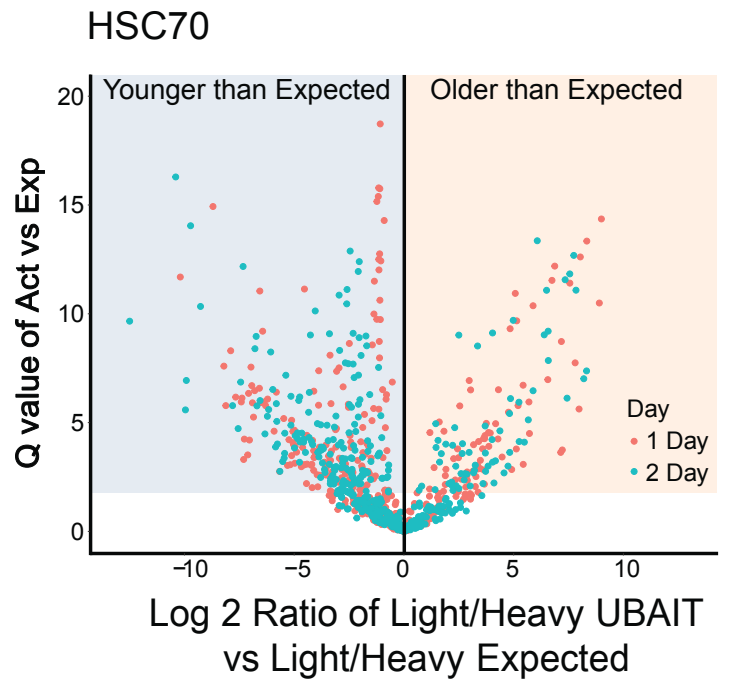

B

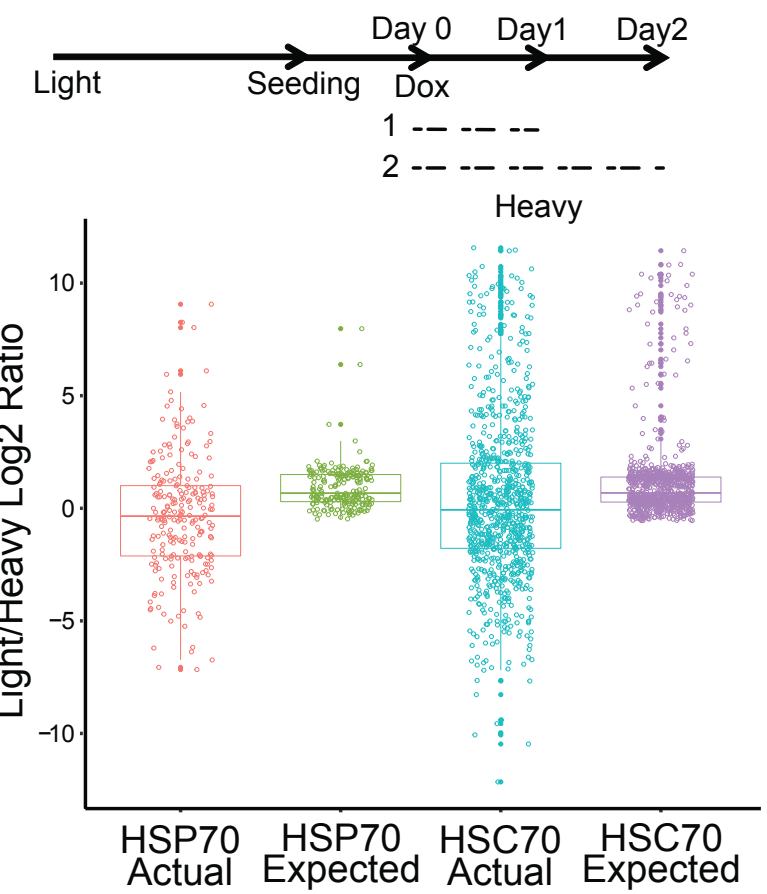

HSP70

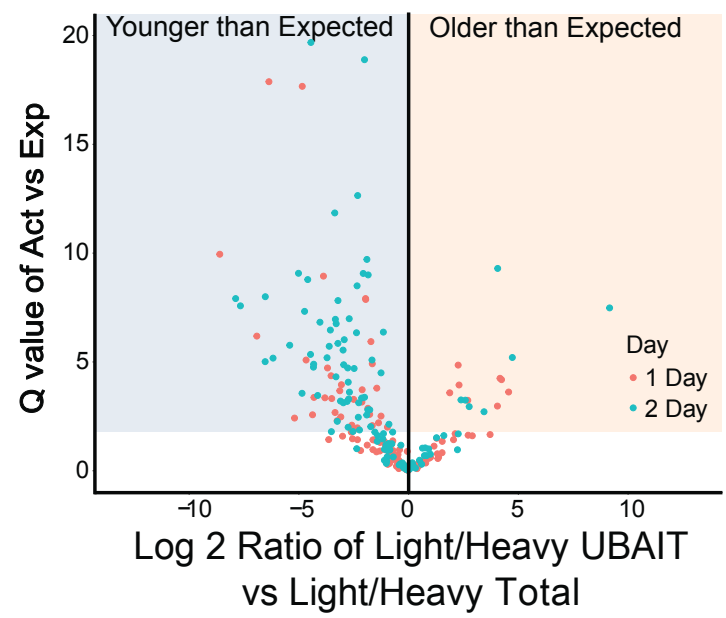

$\mathrm{F}$

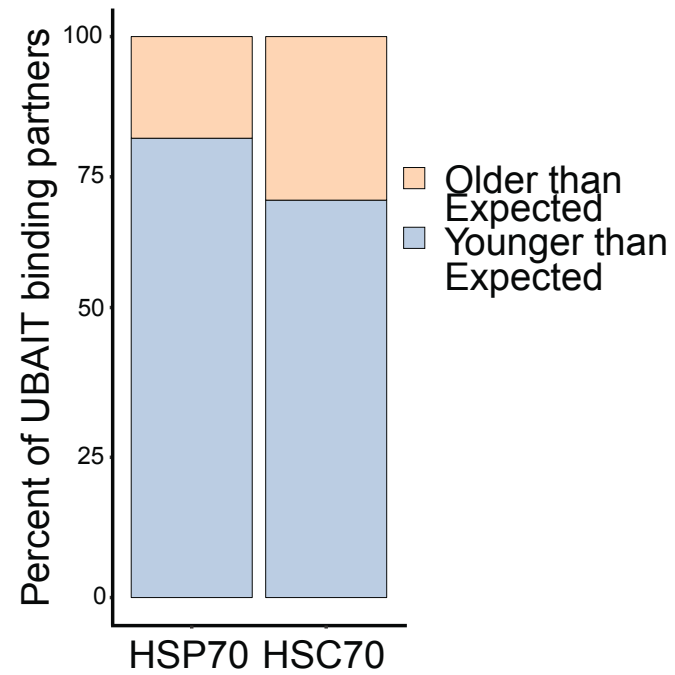


Cian \$ioRxiv preprint doi: https://doi.org/10.1101/865030; this version posted December 4, 2019. The copyright holder for this preprint (which was

Figure 3ot certified by peer review) is the author/funder, who has granted bioRxiv a license to display the preprint in perpetuity. It is made available under aCC-BY 4.0 International license.

A
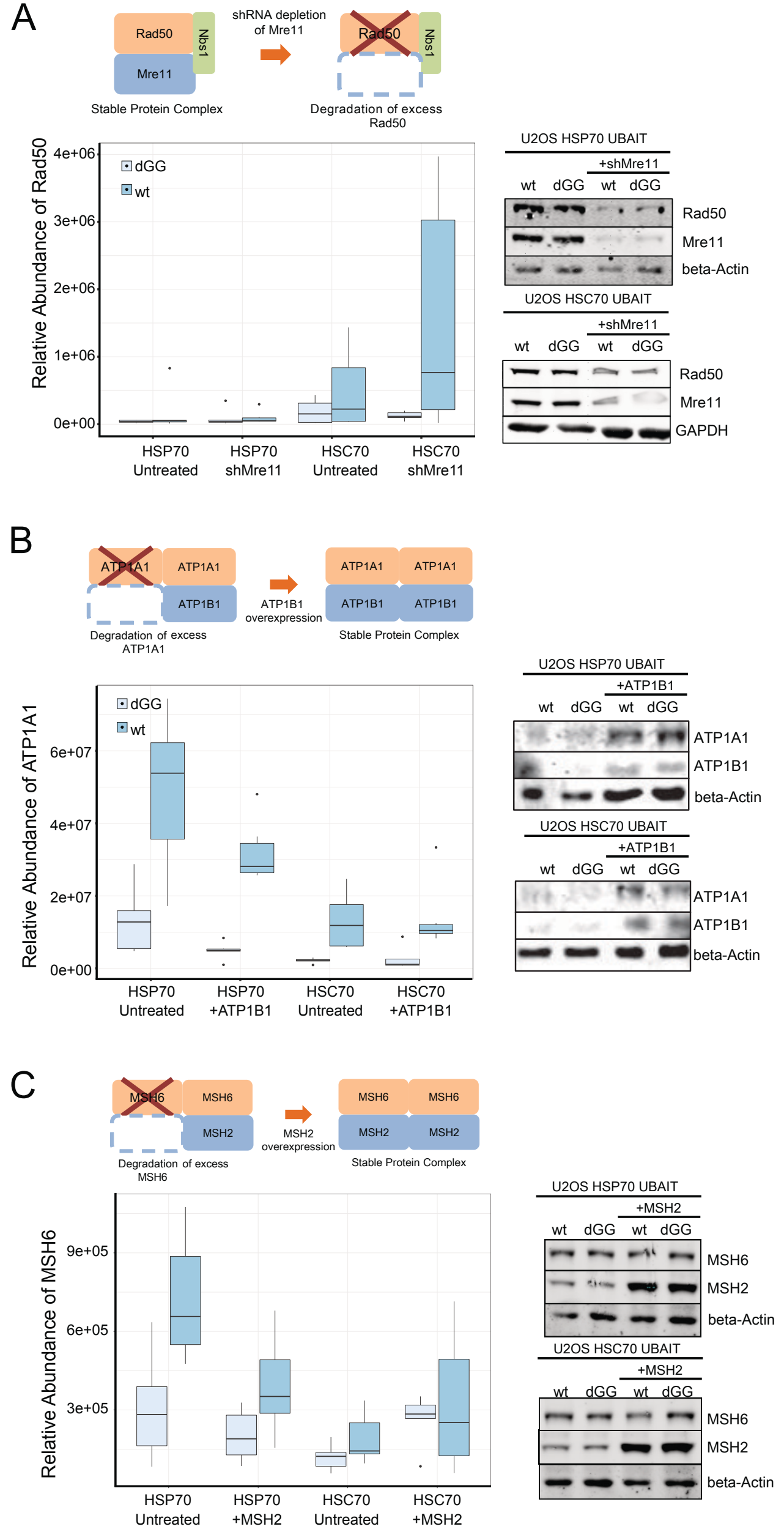
pioRxiv preprint doi: https://doi.org/10.1101/865030; this version posted December 4, 2019. The copyright holder for this preprint (which was thot certified by peer review) is the author/funder, who has granted bioRxiv a license to display the preprint in perpetuity. It is made available under aCC-BY 4.0 International license.

A

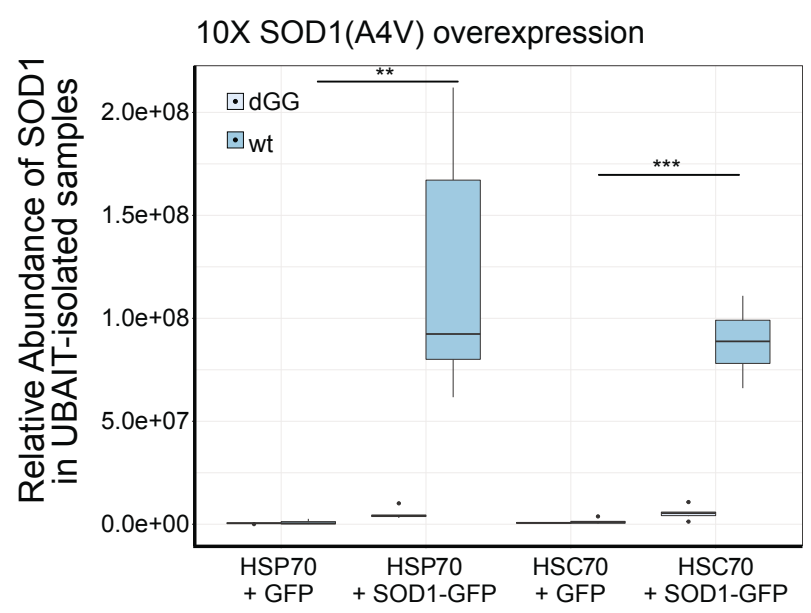

C

\begin{tabular}{|c|c|c|c|}
\hline \multirow{2}{*}{} & \multicolumn{3}{|c|}{ HSP70 } \\
\cline { 2 - 4 } & Untreated & SOD1 A4V OE & P-Value \\
\hline WALTZ & 1210.051 & 1138.808 & 0.2635 \\
\hline TANGO & 2311.042 & 2318.57 & 0.4884 \\
\hline AA Length & 624.12 & 617.82 & 0.4501 \\
\hline & \multicolumn{3}{|c|}{ HSC70 } \\
\cline { 2 - 4 } & Untreated & SOD1 A4V OE & P-Value \\
\hline WALTZ & 1122.793 & 1278.066 & 0.1156 \\
\hline TANGO & 2093.333 & 2548.502 & 0.04226 \\
\hline AA Length & 560.28 & 708.43 & 0.01212 \\
\hline
\end{tabular}

E

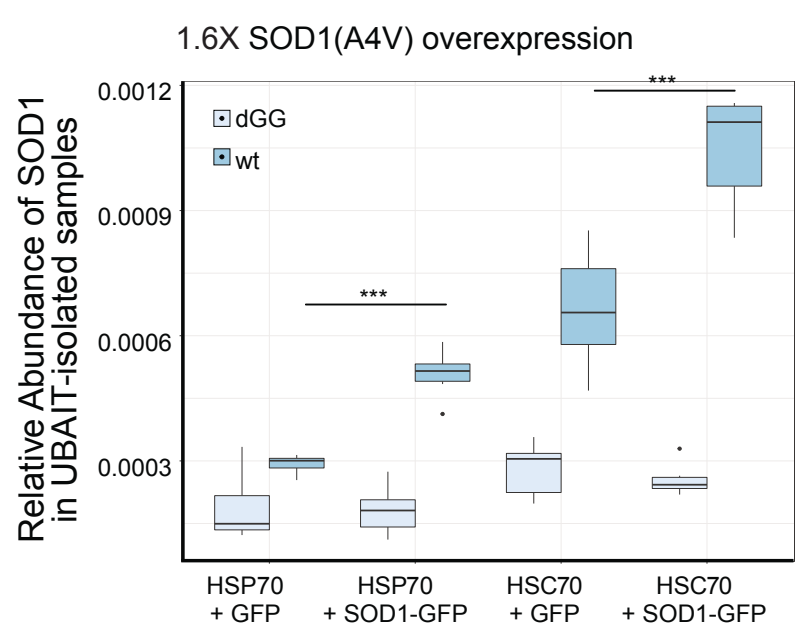

F

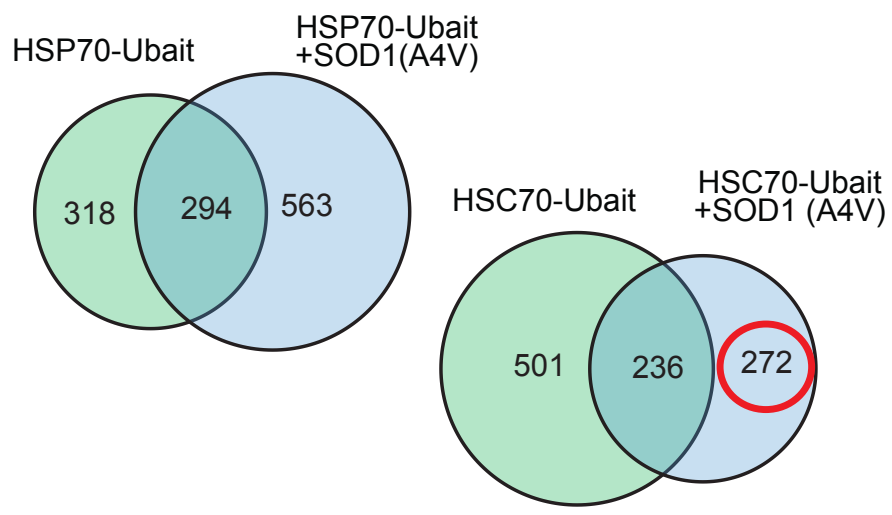

B
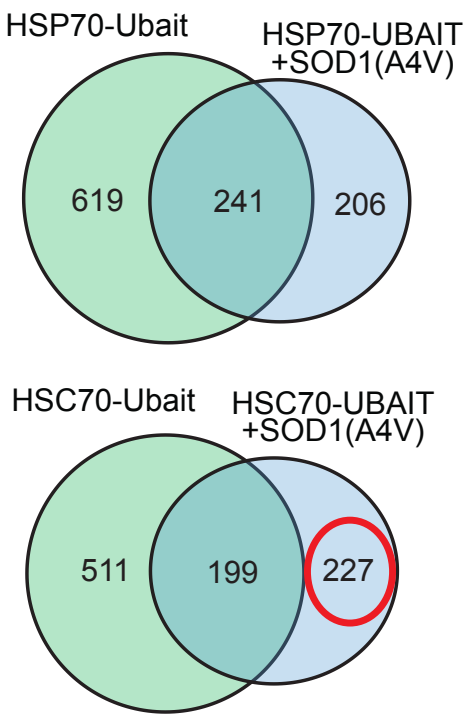

detergent-resistant aggregates:
620 proteins showing reduced aggregation with SOD1(A4V) expression ( $p<0.05$ only)
293 proteins showing increased aggregation with SOD1(A4V) expression ( $p<0.05$ only)

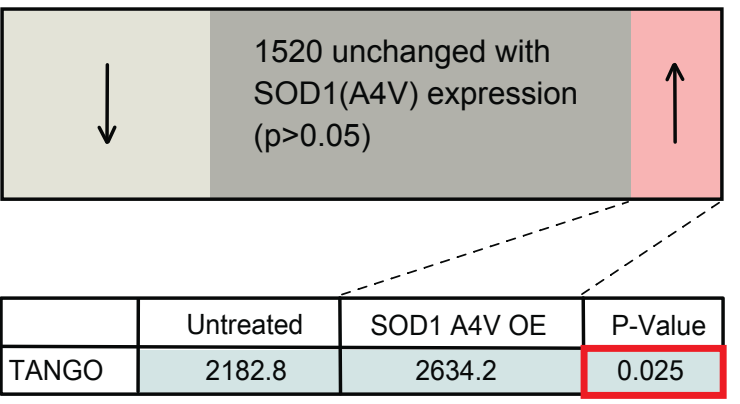

G

\begin{tabular}{|c|c|c|c|}
\hline \multirow{2}{*}{ Waltz } & \multicolumn{3}{|c|}{ HSP70 } \\
\cline { 2 - 4 } & Untreated & SOD1 A4V OE & P-Value \\
\hline Tango & 1117.295 & 1199.392 & 0.1818 \\
\hline AA Length & 2285.333 & 2509.054 & 0.146 \\
\hline & 609.9072 & 632.7357 & 0.2982 \\
\cline { 2 - 4 } & Untreated & SODC70 A4V OE & P-Value \\
\hline Waltz & 1133.681 & 1333.127 & 0.04776 \\
\hline Tango & 2134.442 & 2604.228 & 0.03272 \\
\hline AA Length & 604.804 & 642.7912 & 0.2229 \\
\hline Two sample T-test one tailed \\
\hline
\end{tabular}


bioRxiv preprint doi: https://doi.org/10.1101/865030; this version posted December 4, 2019. The copyright holder for this preprint (which was not certified by peer review) is the author/funder, who has granted bioRxiv a license to display the preprint in perpetuity. It is made available under aCC-BY 4.0 International license.
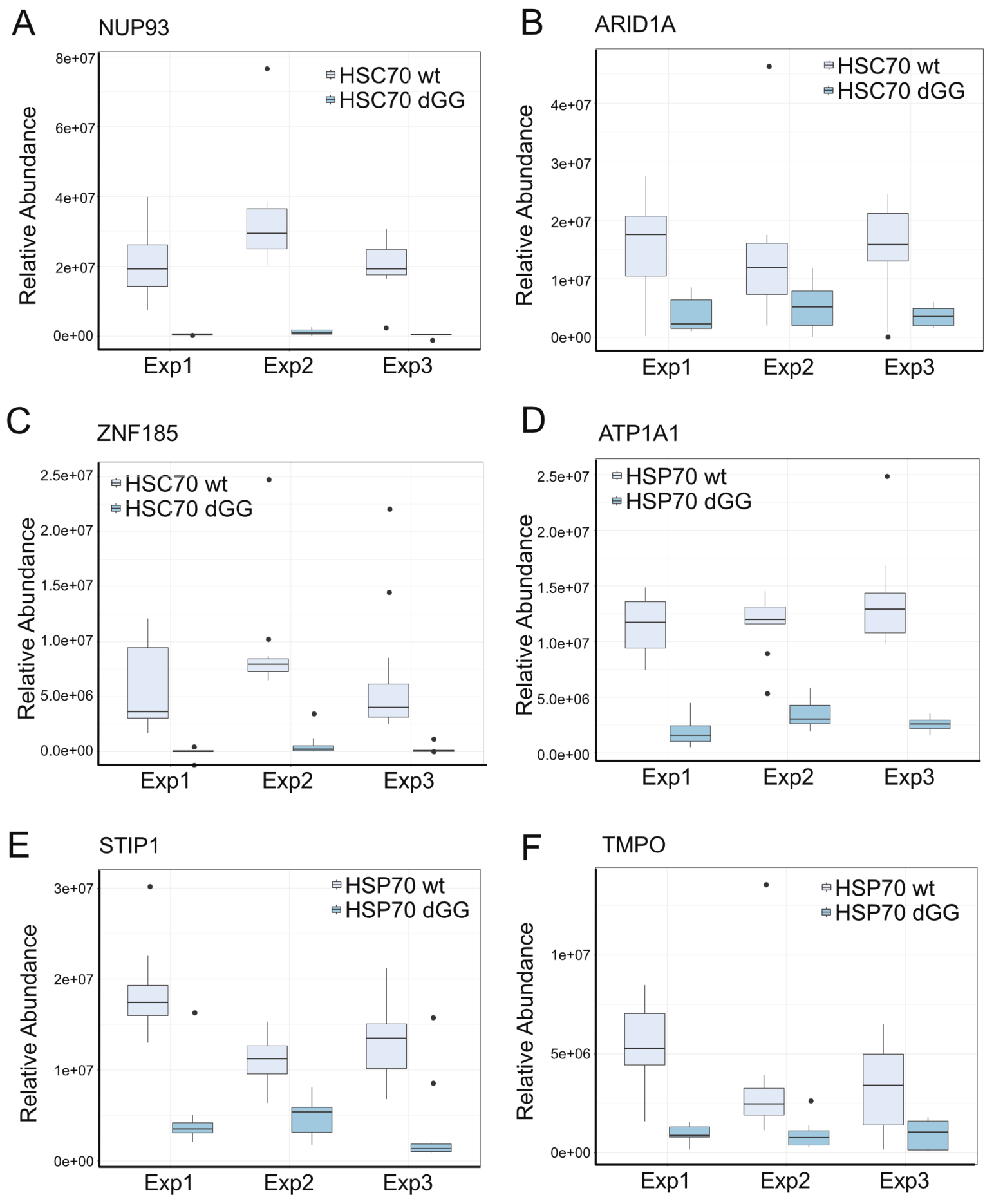

Figure S1. Examples of target enrichment in HSP70 and HSC70 UBAIT isolations. (A, B, C) Levels of binding of specific targets to HSC70 UBAIT wild-type or $\triangle \mathrm{GG}$ isolations (normalized by level of HSC70 expression), with 12 replicates shown per sample. (D, E, F) Levels of binding of specific targets to HSP70 UBAIT wild-type or $\triangle G G$ isolations (normalized by level of HSP70 expression). All examples shown yield enrichment values that exceed the 95\% confidence interval and are retained at FDR 0.05 using BenjaminiHochberg (see Materials and Methods for details). 
bioRxiv preprint doi: https://doi.org/10.1101/865030; this version posted December 4,2019 . The copyright holder for this preprint (which was not certified by peer review) is the author/funder, who has granted bioRxiv a license to display the preprint in perpetuity. It is made available under aCC-BY 4.0 International license.

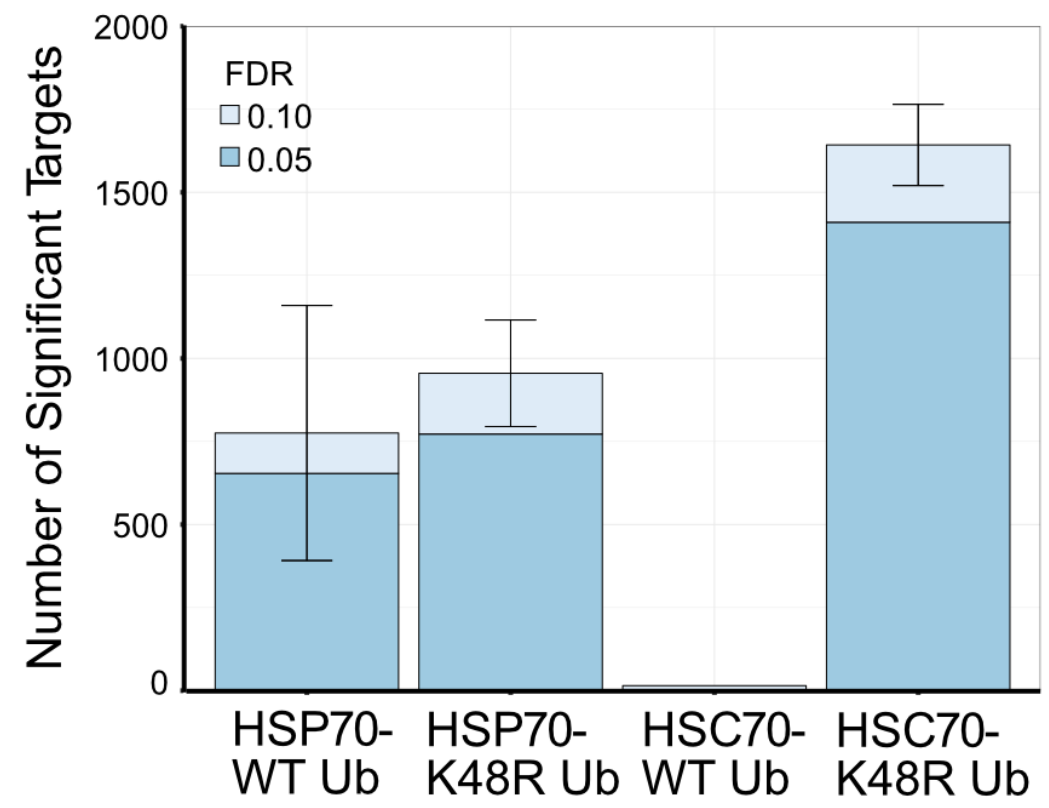

Figure S2. Significant targets identified from HSP70 or HSC70 UBAIT isolations containing either wild-type ubiquitin or K48R ubiquitin. (K48R Ub: $\mathrm{N}=3$ groups, 12 samples wild-type and 12 samples $\Delta G G$ each; WT Ub: N=2 groups, 12 samples wild-type and 12 samples $\Delta G G$ each). Error bars show standard deviation. 


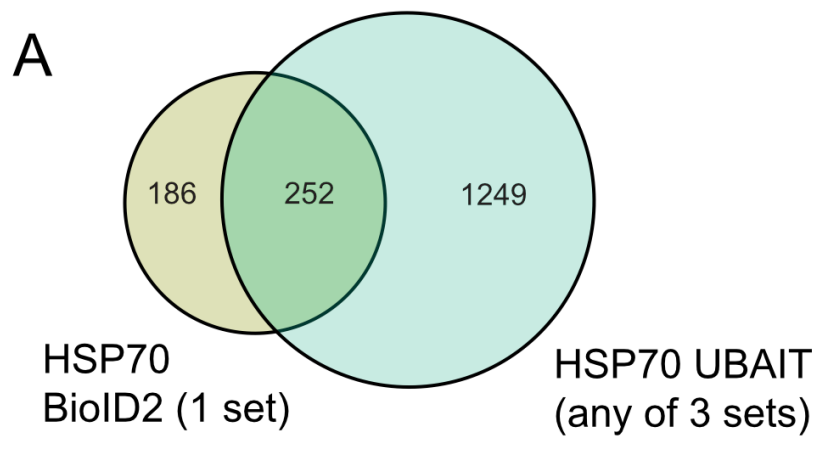

C

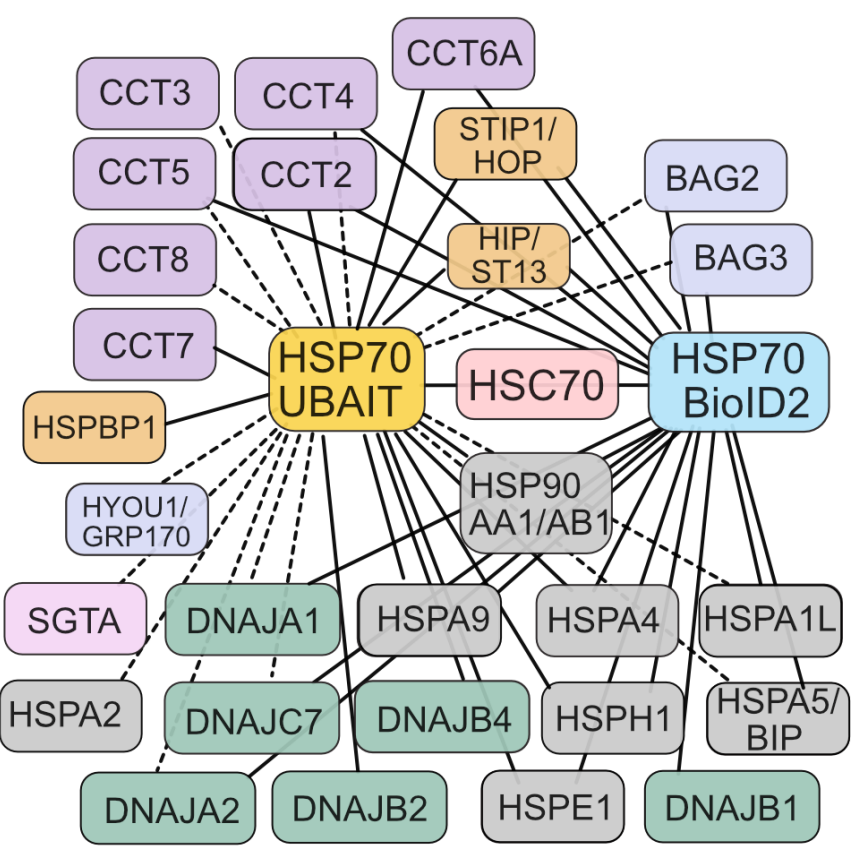

$E$

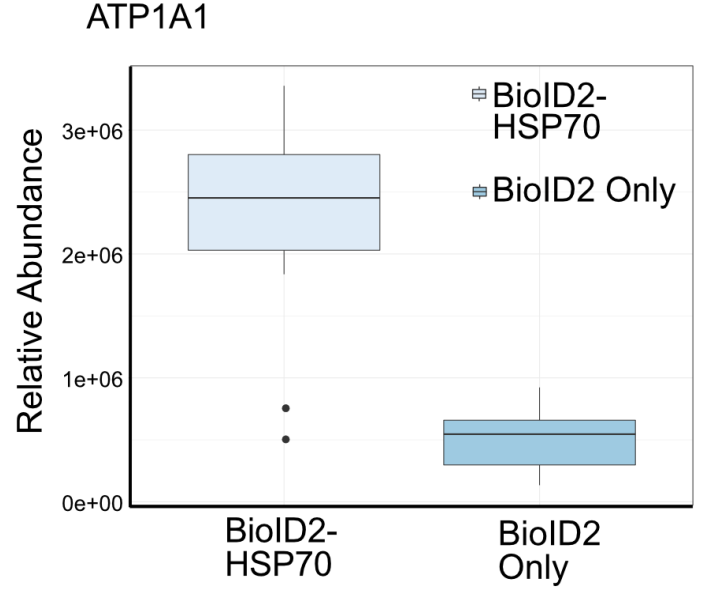

B
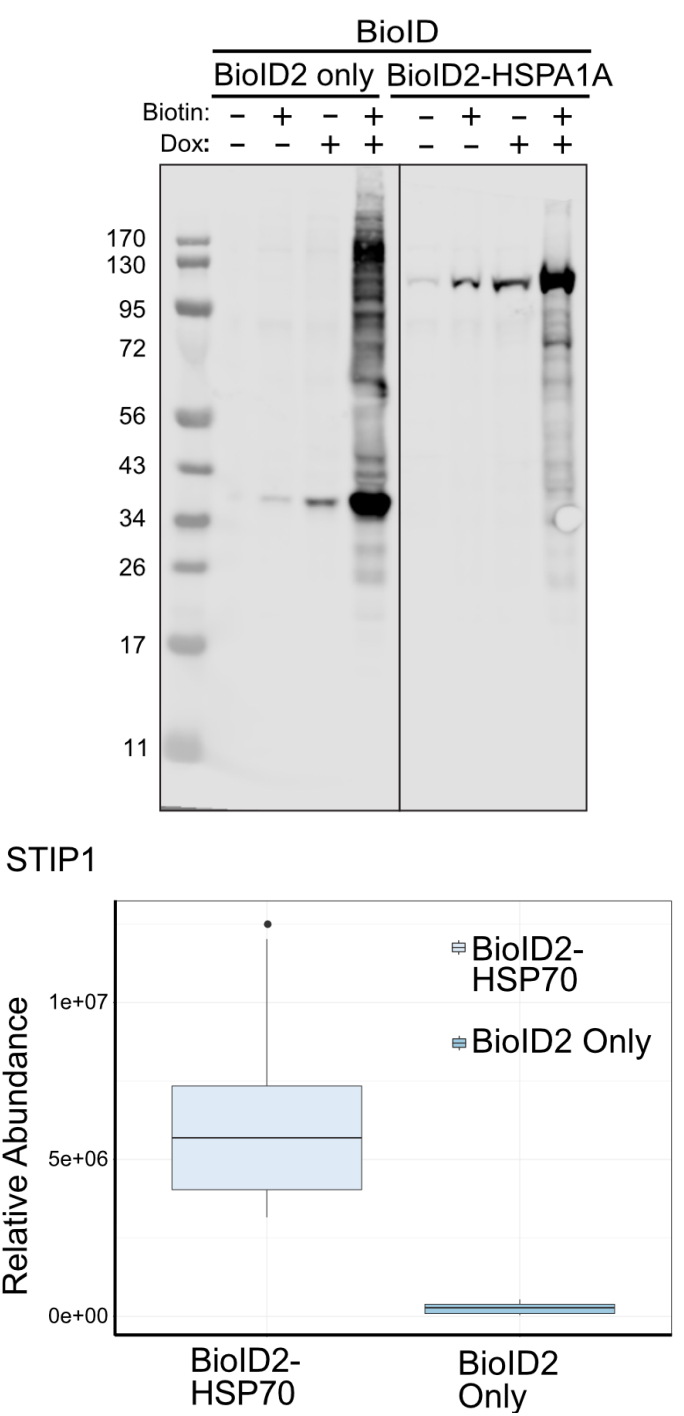

F TMPO

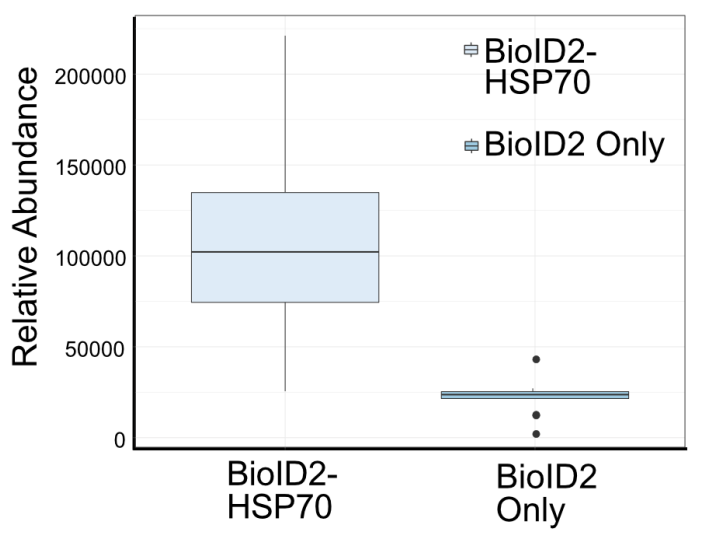

Figure S3. BiolD identification of HSP70 binding partners. (A) Number of HSP70 binding partners identified by BiolD2 (12 replicates (1 set)) compared to HSP70 UBAIT (significant at FDR 0.05 in at least one set). (B) Western blot of inducible BiolD2 and BiolD2-HSP70 fusion protein expression in U2OS cells with additional biotin and doxycyline addition as indicated; visualized with streptavidin-AlexaFluor680 (Life Tech.). (C) Schematic diagram of targets identified through BioID2-HSP70 and UBAIT HSP70. Targets found in one or two sets (but not all three) UBAIT experiments are shown with a dashed line. (D, E, F) Levels of binding of specific targets to BiolD2-HSP70 or BiolD2 alone. All examples shown yield enrichment values that exceed the $95 \%$ confidence interval and are retained at FDR 0.05 using Benjamini-Hochberg (see Materials and Methods for details). 